\title{
THE COLOURFACTORS OF THE SEEDCOAT IN PHASEOLUS VULGARIS L. AND IN PH. MULTIFLORUS WILLD.
}

by M. J. Sirks.

(with 3 coloured plates).

Researches into the various genetic factors, responsible for the different colours and patterns in the seedcoats of Phaseolus vulgaris L. and of Ph. multiflorus Willd. have already been published by several writers, These researches may be divided into two groups, considering the different ways, by which the results have been obtained.

In the first place it will be possible to study these factors by means of artificial hybridizations between plants, belonging to different races of one of these species or by species-crossing and analizing the resulting $\mathrm{F}_{2}$-generations; if necessary the $\mathrm{F}_{3}$ - and further generations may be cultivated as well. In this way the differences in genotypic constitutions of both parents may be found out, as papers of MENDEL (1865), TschermaK (1901, 1902, 1904, 1912), Emerson (1902, 1904, 1909 a and b), Shull (1908), Shaw and Nortion (1918), Tuebres and Koolman (1919, 1921) and KooIMAN (1920) have shown. A great many genetic factors have been discovered by these authors The artificial hybridization of gardenbeans however is not at all easy, as Tschermak $(1901$, p. 706) first has pointed out; only a small percentage of crossings will give good results. And in the scarlet-runnerbean artificial crossing. seems to be still more difficult.

Therefore another way may be gone with sufficient results: in Phaseolus spontaneous hybridization is rather frequent and its products supply us with an excellent material for the study of the genetic factors. In these cases one of the parents only, the motherplant, is known with certainty, but the fatherplant can be indicated frequently with more

Genetica IV. 
or less probability, and moreover in many cases it is perfectly immaterial in these researches that the fatherplant is unknown. For all crosses, made with a white-seeded plant as one of the parents, have the same shortcoming because of the uncertainty in its genotypic constitution of this white plant; one and the same white race of beans may contain plants very different in factorial constitution with regard to the seedcoat-characters; as now known a white-seeded plant is white because of lacking a certain groundfactor, but it may contain a great many other factors, that remain unvisible because of the absence of the groundfactor. Thus spontaneous hybridization may offer to us a very welcome subsidiary material for researches; their analysis has been applied by Kajanus (1914), Lundberg and Aakerman (1917), Tuebres and Koolman (1919), Sirks (1920). Such an analysis is only complete, if all seeds from an $F_{1}$-plant, that originated by spontaneous hybridization, are available and accordingly the whole $\mathrm{F}_{2}$ - and following generations can be grown; only the papers of LUNDBERG and AAKERMAN and my own have been worked out in this manner; Kajanus as also Tuebbes and Koolman have derived their materials from only one seed with a seedcoat divergent from those of the race of origin. Of course this seed had been developed upon an $F_{1}$-plant, and the embryo contained in it, was thus an $\mathrm{F}_{2}$-individual. This does not necessarily involve an essential fault, so less as the little number of $\mathrm{F}_{2}$-individuals gives in simple cases only a sufficient result, but notwithstanding a danger remains and an important difficulty may not be disregarded. The posterity of this seed, grown as $F_{3}$. generation, may be wholly uniform, and in that case its importance for a genotypic analysis of the parents fails, and secondly this $\mathrm{F}_{2}$. individual will in most cases possess only a part of the whole number of genetic factors, that was present in the $F_{1}$-plant and so in the $F_{2}$-generation. It will be even conceivable, that the $F_{2}$-plant grown, lacks all seedcoatfactors present in the known motherplant, and the analysis of its $\mathrm{F}_{3}$-generation will be therefore very deceiving. In many cases growing the whole $\mathrm{F}_{2}$-generation is necessary, and growing the whole number of $\mathrm{F}_{3}$-families obtained very much desired for founding sound conclusions.

In this paper a review will be given of the results obtained by previous authors and of the genetic factors for the seedcoatcolours 
in the species above named, as established by them; results of newly grown artificial and spontaneous crossings will build the second part. The previous literature is arranged according to the factors, discussed therein; the results of my own researches will be given in connection with the crosses, by which they have been detected.

\section{PREVIOUS LITERATURE.}

\section{a. Phaseolus vulgaris.}

In his classic paper MENDEL (1865) has already given some notes upon the results of a cross between Ph. vulgaris (Ph. nanus L.) as mother and Ph.multiflorus Willd. as the male plant. The firstnamed species had white seedcoats, the father showed seeds with a black spotted and marbled pattern upon a peach-red groundcolour. The seeds of the hybrid were like those of the fatherplant; in the $F_{2}$ generation 30 coloured and only one white plants were obtained and this proportion encouraged the genius of MENDEL to establish the now well-known principle of polymeric factors, „if only we might assume that colour of the flowers and seeds of $P$. multiflorus is a combination of two or more entirely independent colours, which individually act like any other constant character in the plant". MENDEL's rather scarce materials were not sufficient for a more detailed analysis and a more conclusive exposure.

In the first year after the reviving of mendelism, TschERMAK as first has tried to obtain numerical proportions from his bean-crossings; a number of papers has been published since by this author relative to these researches. His first contribution (1901) to our knowledge of these colourfactors had only the $F_{1}$-generations in view, and the value of the characters, in which both parents were different; the $\mathrm{F}_{2}$-cultures and the numerical proportions resulting from them, were published in 1902. Summarizing papers, giving more new data, have appeared in 1904, and later on, in 1912. With regard to the pair of factors: coloured-white, his results in a very extensive material followed the mendelian proportion $3: 1$, not only for the whole of his cnltures; but also in regard to these cultures, as taken one for one. He found indeed in some of his $\mathrm{F}_{2}$-families from crossings between coloured and white races 488 coloured against 161 white 
plants; in c-w-splitting $F_{3}$-families $596 \mathrm{c}: 177 \mathrm{w}$ and in c-w-splitting $F_{4}$-cultures 226 coloured: 78 white plants, or totals of 1310 coloured : 416 whites, or $3.15: 1$. In 1912 TsCHERMAK has indicated this chromogenic groundfactor, the absence of which makes the seedcoat white, while presence or absence of other colourfactors is of no importance, as A. And EMERson has published like results in his papers (1902, 1904, 1909 a and b), that form excellent complements to Tschermaks researches. Crosses between coloured and white-seeded plants in Phaseolus vulgaris gave in his cultures in $F_{1}$ always coloured seedcoats, in $F_{2} 280$ with and 111 without pigmentation, and in splitting $F_{3}$-families 191 coloured 70 white plants. Nearly a 3:1- proportion, that led EMERson to the conclusion of the presence of a factor $P$ for pigmentation : $p$ or the absence of $P$ giving white seedcoats. This factor has since been found by SHuLt, SHAw and NorToN and myself and indicated as $\mathrm{P}$; TJEBbEs and Koolman (1919) named it $\mathrm{F}$ and Kooman (1920) again A. With regard to its absence all authors are unanimous; while it remains uncertain, if its presence without the other colourfactors, involves any observable result. TscHeRMAK (1912) ascribes to the unaccompanied presence of his chromogenic groundfactor a yellowbrown colour (as shown by his yellowish brown race "Non plus ultra" with formula $A$ bcm), while EMERSON $(1909$, p. 100$)$ is of another opposite opinion: crossing of two coloured beans, that have no common colourfactors, may led to the birth of a certain percentage of white-seeded $F_{2}$-plants, as in these cases the white colour is caused by the absence of all pigment-building factors and presence of the P-factor only. Crossing a white bean, produced in this way with another white one, that lacks the factor for pigmentation, but possesses other colourfactors, will give therefore a coloured $F_{1}$-generation. And Shaw and NorTon $(1918$, p. 65) have obtained indeed a coloured posterity by crossing two whites (Davis Wax $\times$ Michigan White Wax). It may be regretted, that they have, as far as I know, not yet published more detailed results about the posterities, grown from this important hybrid. The existence of two types of white-seeded plants implies that not all $F_{2}$-generations from a coloured-white crossing : will segregate according to $3: 1$; if the white parent (p) has not all other factors in common with the 
coloured (P) one, the proportions in $F_{2}$ will vary from $2.4: 1$ to $3: 1$, dependant on the presence of a few or more factors in both parents $\left(\mathrm{Pa} \mathrm{B} \times \mathrm{pAb}\right.$ for instance will segregate in $\mathrm{F}_{2}$ in the proportion 45 coloured : 19 white). White beans lacking the P-factor as also the other colourfactors, will show a segregation when crossed with coloured ones, between 1.3 coloured: 1 white and 3 coloured: 1 white (e. g. $\mathrm{PA} \times \mathrm{p}$ a gives in $\mathrm{F}_{2} 9$ coloured : 7 white plants). And finally the splitting after crossing of a white plant, possessing the P.factor but without the other ones, and a coloured bean, will show proportions between $\infty: 1$ and $3: 1$; these proportions follow the scheme of polymeric factors $3: 1,15: 1,63: 1$ and so on.

2. The second character, studied first by Tschermak and since by other writers also, is that of the marble-pattern. In the researches, relating to this character, an essential difference between two types of marbled patterns was discovered. In crossings between beans with marbling as a constant racial character, and selfcoloured plants, the marble pattern is dominant, with a segregation of 3 marbled: 1 selfcoloured in the $F_{2}$-generation (Tschermak $58: 20$, Emerson $331: 124$, Tuebres and Kooman $69: 22,130: 51$ a. o.). But besides the action of this dominant racial character, marbling was found by Tschermak in his first crosses already to appear in another genetic form: some crosses between selfcoloured and white plants gave as "novum" a marbled $F_{1}$.generation and in these cases the segregation in $F_{2}$ families showed to be $1: 1$, for he found in these cultures 284 marbled: 263 selfcoloured, in $\mathrm{F}_{3}$-families $218 \mathrm{~m}: 234 \mathrm{~s}$ and in $\mathrm{F}_{4}$ 's $91 \mathrm{~m}: 93 \mathrm{~s}$ or as totals 593 marbled plants : 590 selfcoloured ones. In his $F_{3}$ and $F_{4}$-cultures no one marbled individual gave a uniform posterity: all families descended from marbled $F_{2}$ - and $F_{3}$-plants segregated according to the proportion $1: 1$. In crossings, giving whites besides coloured descendants, the proportions were 6 marbled: 6 selfcoloured : 4 white plants. Moreover this eversporting marbling was observed in crosses between two selfcoloured individuals, as (Tschermak 1904 , p. 34 of the separate) the uniform black race "Schwarzer Neger" crossed with the light yellowish brown "Hundert für Eine”. SHAW and Norton (1918, p. 71) have obtained in their crosses between Blue Pod Butter, with a yellowish brown seedcoat, and 
other uniformly coloured races, $\mathrm{F}_{1}$-generations with marbled seeds and segregating in $F_{2}$ into 1 marbled : 1 selfcoloured (for example $237 \mathrm{~m}: 239$ s).

In addition to this Koolman (1920, p. $36 \mathrm{ff}$.) reports to have found that not all $\mathrm{F}_{3}$-families, descended from marbled $\mathrm{F}_{2}$-plants, show this $1: 1$-proportion. His $\mathrm{F}_{2}$-family segregated into 75 marbled : 71 self coloured individuals, but among the $\mathrm{F}_{3}$-cultures a great many splitted up according to $2: 1$ (46 marbled : 26 uniformly coloured), so that $66^{2} / 3$ of the total had marbled seedcoats, while in other $\mathrm{F}_{3}$-families the percentage of marbled individuals was $53.3 \%$, in still others $50 \%$.

The discussions of this phenomenon have gone through a great many changes. At the beginning both types of marbling: the constant and the eversporting form were sharply separated; the firstmentioned type was caused in Tschermaks opinion by only one dominant mendelian factor; the other was an eversporting character, called up from a state of latency, in which it was present in the uniformly coloured race. Afterwards (1908) SHull has supposed this latent character as being present in the white parent, and this factor $M$ would be observable in heterozygotic condition only; $M M$ as also $\mathrm{m}$ m-individuals are therefore uniformly coloured, $\mathrm{M} \mathrm{m}$ individuals are marbled. Constant marbling was in his opinion caused by a separate dominant factor. EMERSON had at first accepted this hypothesis as proposed by SHULL, but in a later paper (1909 b) he has changed his opinion and preferred another hypothesis, the proposal of which had been made by SpILLMaN. This author thinks, that races with constant marbling may possess two factors in absolute linkage, that would remain always together in the gametes; being separated from each other these factors would be invisible.

Thus three forms of selfcoloured beans could exist: one with one of these marbling factors, but lacking the other; a second type possessing the other, but missing the first one and as third. case a bean, in which both factors fail. If we call with EMERSON these factors $Y$ and $Z$, so in collaboration with the pigmentationfactor $P$ four types of coloured and four types of white beans may exist, vìz.:

$1 \mathrm{P}$ Y $\mathrm{Z}=$ marbled.

2 P Y $\mathrm{z}=$ selfcoloured, with one latent marbling factor. 
$3 \mathrm{P}$ y $\mathrm{Z}=$ selfcoloured, the other marbling factor being latent.

$4 \mathrm{P}$ y $z=$ selfcoloured, both marbling factors being absent.

5 p $\mathrm{Y} Z=$ white, with both marbling factors latent.

6 p Y $z=$ white, with one latent marbling factor.

7 p y $Z=$ white, the other marbling factor being latent.

8 p y $z=$ white, without any marbling factor.

In this hypothesis of SpIllman both types of marbling are taken together; one possessing both absolutely linked factors $\mathrm{X}$ and $\mathrm{Y}$ in a permanent state, giving thus by their collaboration a constant marbling and pretending the presence of only one dominant factor; the other, inconstant type of marbling would result after crossing two selfcoloured races (or a white race with a selfcoloured one), each of which possesses one of these two factors $\mathrm{X}$ or $\mathrm{Y}$. Emerson did not emphasize the absolute repulsion, that musi take action in these crossings, a supposition necessary for an explanation of the numerical proportions $(1: 2: 1)$ resulting in the $F_{2}$-generation. This supposition however seems to be very well tolerable if the cases known from other researches about coupling and repulsion are taken into consideration.

To this seemingly very plausible hypothesis KooIman has objected, that by it the numerical proportions in some of his $F_{3}$ families cannot be explained (he observed sometimes $66.6 \%$ of marbled, in other cases $53.3 \%$ of marbled individuals in the whole of coloured $\mathrm{F}_{3}$-plants). The firstmentioned proportion was apparent in families, that gave a great number of whites; the segregation followed almost along 1 selfcoloured: 2 marbled: 1 white. The families with $53.3 \%$ of marbled individuals showed a segregation of 8 marbled: 7 selfcoloured: 1 white. From these results, Koolman has derived as his opinion, that inconstant marbling may be caused by a special chromogenic factor in a heterozygotic state. He calls $A$ the groundfactor for pigmentation, that alone causes a white seedcoat, but is necessary for the apparence of other colour factors, that remain invisible, if $A$ is absent. $A$ chromogenic factor $B$ gives in collaboration with $A$ a coloured seedcoat, with exception of a small ring around the navel. If only $A$ and $B$ are present, the seedcoat is light lemoncoloured. This chromogenic factor B in Koolmans opinion would cause in heterozygotic state the inconstant marbling. The $\mathrm{F}_{2}$-generations from a 
hybrid A A B b segregate into three groups : 1 A A B B:2 A A B b : 1 A A b b or 1 selfcoloured : 2 marbled : 1 white. Segregations from an A A B b C c-hybrid, in which $C$ in collaboration with $A$ causes a colouring of the whole seedcoat, the navelring inclusive, go according to $1 \mathrm{~A} \mathrm{~A} \mathrm{~B} \mathrm{~B} \mathrm{C} \mathrm{C} \mathrm{:} 2$ A A B B C c : 1 A A B B c c : 2 A A B b C C : 4 A A B b C c : 2 A A B b c c : 1 A A b b C C : 2 A A b b C c: 1 A A b b c c ; these 16 combinations may be grouped into 8 marbled (all with $B$ b), 7 selfcoloured and 1 (A A b b c c) white; thus a proportion of 8 marbled : 7 selfcoloured or $53.3 \%$ of marbled individuals. These results have led KooIman to his opinion that the factor for constant marbling (called by him $\mathbf{M}$ ) would be of a character essentially different from his B-factor. This $M$-factor is dominant over the recessive uniformity in colour, and shows an $\mathrm{F}_{2}$-segregation along $3: 1$.

Besides marbling as seedcoatpattern, another design is shown by some races: a striping, by which the colours are restrained to long, almost ellipsoidical stripes with the navel in one of the long sides of these ellipses. This character also may be ascribed to one dominant factor, by most authors indicated as $\mathrm{S}$ with monohybridical segregation. Tschermak believes this factor $S$ to be hypostatic to the marbling factor $M$.

As last factor for special designs the factor or factors for eyedness may be mentioned. This peculiar colourpattern was studied by EMERSON; from his observations on its segregation he concluded to the existence of a pair of factors $T-t ; T$ causes the extension of the colour upon the whole seedcoat (totality); in $t$ - individuals this colour is restrained to a relatively small part around the navel, as an eye of pigmentation. Totality of colour was dominant in $F_{1}$; the $F_{2}$ segregated into 3 total-coloured: 1 eyed individuals. Concerning this T-factor EMERson suggested the possibility of its presence in white beans in a state of latency. Thus four genotypes may be found : PT $=$ totally coloured; $\mathrm{Pt}=$ eyed, $\mathrm{pT}$ and $\mathrm{pt}$ whites, one with the other without the latent factor for total colouring.

Of course it will be possible, as EMERSON already has remarked, that more genetic factors are at work in the process of colourextension : for example besides P.p and T-t still another pair E.e, that 
causes the colourdevelopment in the eye itself. Thus eight different genotypic combinations may be realized: (1) P T E, (2) P T e, (3) P t E, (4) P te, (5) p T E, (6) p T e, (7) p t E, and (8) p te. Numbers 1 and 2 are totally coloured individuals ( $E$ is supposed to be hypostatic to $T$ ); eyed beans occur in number 3 , and the other combinations $4-8$ have white, colourless seeds. Besides the possibility remains, that different factors $\left(E^{\prime}, E^{\prime \prime}\right)$, are to be accepted for the distinctive types of pigmentextension. For there are races of beans, that show within narrow limits of fluctuations, the pigment restrained to a very small spot around the navel, while in other races the pigmentextension occupies a third or more of the whole seedcoat. And this pigmentextension is an essential character of the race.

By the way it may be mentioned, that in Vigna sinensis also a factor for totality has been discovered (SPILlmaN 1913, MANN 1914, Harland 1919), leaving in its absence only a part of the seedcoat coloured, while the rest is white.

The further factors, as discovered in researches that have been published till now, are those concerning the various colours and colourintensities, so much characteristic for the seedcoats of Phaseolus vulgaris. TsCHERMAK in his earlier papers already has made an effort to divide both groups of coloured individuals: the marbled contained three colourdifferences (black, violet and brown) and these three groups occurred in the proportions of 9:3:4 (92 blackmarbled : 33 violetmarbled : 38 brownmarbled, thus in more precised proportion $9: 3.23: 3.72$ ); the selfcoloured ones however showed the reverse proportion of 4 blacks: 3 violets: 9 brown (39 black: 27 violet: 101 brown, or $4: 2.77: 10.36$ ). These results of TsCHermak's paper may be tabulated in this manner:

pigmented 3

white 1 marbled 1 selfcoloured 1

B1. M. 9 : V. M. 3 :Br. M. 4 . Bl. S. 4 : V. S. $3:$ Br. S. 9.

A more detailed grouping of the colours met with a great many difficulties and uncertainties concerning the conclusions for the genotypic differences: a few proportions only (brownmarbled: yellowmarbled and full-black : brownish-black) showed to follow a simple mendelian relation $3: 1 \quad(30: 8$ and $29: 10)$; in other cases the proportions of segregation were less clear. For explaining these 
segregations, TschermaK has suggested the existence of two colourfactors besides the groundfactor $A$, that is necessary for the appearance of colour in beans, viz. B causing a violet colouring, and $C$ colouring in coopperation with $A$ alone the seedcoat with a yellowish brown colour; $B$ and $C$ together with $A$, would give a black seedcoat. The factor $B$ according to Tschermak, may be divided into two components $B_{1}$ and $B_{2} ; B_{1} \quad B_{2}$ as also $B_{1} b_{2}$ giving a violet colour, $b_{1} B_{2}$ a red one.

EMERSON has, in the footsteps of SHull, supposed four colourchanging factors to be present in various races of beans: $O$ changing yellow into orange-brown, $D$ giving darkbrown and $B$, changing darkbrown into black; $R$ a factor causing a red colour, would be hypostatic to orange-brown, this orange-brown to the other colours a.s.o.

In later years KaJANus (1914) has given some results of spontaneous crossings, without pointing out the factors concerned therein; LUNDBERG and AAKERMAN (1917) however did so in founding $G$ as the factor for a yellowish-brown colour, and $C$ as that for a chocolate-coloured seedcoat; their coöperation results into darkbrown, the absence of both of them yellowish white. Then c c g g $=$ yellowish white, c c GG= yellowish brown, $\mathrm{CCg}=$ chocolate and CGGG= darkbrown. Both these factors would segregate independently with a segregation in $F_{2}$ of $9: 3: 3: 1$.

Researches on a large scale at the Massachusetts agricultural experiment station have enabled SHAW and NorTon (1918) to discover a many colourfactors: besides $P$, the groundfactor for pigmentation, two modifying factors $M$ and $M^{1}$ would give rise to two types of colouring; one, $M$, being present in the beans with yellow.black colours, the other $M^{1}$ in those of the red series. In the authors opinion these factors are enzymes, and necessary for the existence of colours. Further the writers have found factors for black $(G)$, for coffeebrown $(F)$, for yellow $(C)$, for darkred (E), lightred (D) and in one race (Creaseback) still another black factor $X$.

The papers of TuEbBes and Koolman have also unveiled some colourfactors, present in vatious races of gardenbeans. In their first paper (1919) the cross between a common yellow-brown race and a violet-striped one was studied: the genotypic formula of 
the first race was supposed to be F F B B s (F being the groundfactor for pigmentation, $B$ giving the yellowish brown colour), that of the violet-striped bushbean of Prague would be FFBBS ; this $\mathrm{S}$ indicating a factor that prevents the brown colour in certain regions of the seedcoat from development and changes the remaining brown into violet. In later years (1921) the writers have changed their opinion concerning the functions of these factors : $S$ would not influence $B$ in the manner described above, but its presence alone results in the development of a violet colour, that is locally confined; these factors $B$, for the brown colour, and $S$ for the violet stripes, show an absolute repulsion in the process of factorial segregation. Further TJEBBEs and KoOIMAN have founded the factors $\mathrm{Z}$ (black colouring), $\mathrm{Bl}$ (blue) and $\mathrm{V}$ (corrosive factor causing a marbling and colourdiluting, that may be realised as a constant racial character).

The analysis of the posterity from a hybrid, spontaneousi $I$ originated gave to me (1920) the possibility of concluding th existence of the following characters: $P$ the groundfactor for coloured seedcoat, that in lonely presence develops a yellowish colour; $G$ the factor for yellowish-brown colour; $\mathrm{L}$ a factor for darkbrown; $V$ a factor for violet colour, being hypostatic to the L.factor; Gr a factor, that gives a grey glot in addition to the other colours, $B$ a factor changing violet into blue, and $S$ a factor for stripes, that restricts the blue, violet and grey colours into stripes. Some of these factors seemed to be linked-somehow.

In another paper concerning this subject, Koorman (1920) has suggested the existence of still other factors in the seedcoats of Phaseolus vulgaris: A the groundfactor for colourdevelopment, B a factor that gives a total colouring of the seedcoat, a small ring around the navel excepted, if presence of $A$ makes a coöperation possible; beans with both factors $A$ and $B$ are lemon.yellow. $C$ is a factor that together with A colours the whole seedcoat, the navelring. included in a brownish colour, while $D$ in presence of $A$ and absence of $B$ and $C$ causes a brown colour of the navelring only, and an almost unobservable grey dotting on the remainder of the seedcoat. Besides these factors, others still are discovered by Koolman: two factors that influence the intensity of the other colours: $E$ intensifying the brown colours, and $F$ that gives a 
violet or grey glow upon them. The B-factor would then, in Koolman's opinion, in heterozygotic state cause the inconstant, exersporting marbled pattern.

\section{b. Phaseolús multiflorus.}

About the colourfactors in the seedcoat of the scarlet-runnerbean and its varieties, our knowledge is more restrained and still less clear than it is concerning $P h$. vulgaris. Besides brief and very incomplete communications of FERMOND and of KOERNICKE (as cited by FruWIRTH 1919. p. 189), there is an observation of REINKE (1915), that would show the white colour as being dominant over the colouring of the seedcoat; because of the important crossfertilization in this species (surpassing to a high degree that of the common gardenbean), some doubts about such an observation should always be held. Further indications may be found in the papers, mentioned above, of MENDEL and of Tschermak, who gave (1912. p. 223) some numbers of segregation showing how uniformly coloured $\mathrm{F}_{2}$ - and $\mathrm{F}_{3}$-individuals may give a descendance of marbled and of selfcoloured plants, in proportions near $3: 1$, while brown-marbled would segregate still blackmarbled, totally blacks and totally violets, and" the violet selfcoloured ones gave some descendants with black seedcoats. Coloured seedcoats would, according to TSCHERMAK be dominant over the absence of colour, or whites. And last, TJebbes and Koolman (1919. p. 334), have told us about a hybrid between the constant marbled $P h$. multiflorus (black pattern on a violet groundcolour) and a white seeded $P h$. vulgaris, from which in $\mathrm{F}_{2}$ a. o. constant-marbled, marbled heterozygotes, constant selfcoloured and segregating selfcoloured individuals descended: The heterozygotes segregated along $3: 1$.

The complexity of these results and the want of clearness concerning the genotypic factors at work in the seedcoats of these species, made a renewed research very desirable, chiefly in collecting many and precise numbers of segregation in relatively simple crosses. In the present paper these researches are treated in connection with the conclusions, derived from them. 


\section{NEW RESEARCHES.}

\section{a. Phaseolus vulgaris.}

The materials, considered in this paper, came for a part from hybrids artificially : obtained, partly from $F_{1}$-individuals that took their origin by spontaneous hybridization. In the first case it was. very easy to grow the whole $\mathrm{F}_{2}$-generation; in the other cases. also the whole posterity of an $\mathrm{F}_{1}$-individual was taken into cultivation. Part of these materials were obtained by the aid of others: Messrs C. J. Droogendijk (The Hague), J. D. Koeslag (Wageningen), Prof. H. Mayer Gmelin (Wageningen) and N. Raap (Anna Paulowna, N.H.) have supplied me friendly with some hybrids.

The pure races, that have been used in these hybridizations, are:

1. "Witte" (white) beans with a shining white seedcoat, lacking. a navelring;

2. "Citroen" (lemon) beans, lemoncoloured, without or at most with a blueish navelring (pl. II, fig. 22);

3. „Wagenaars" have a seedcoat, that immediately after harvesting, is lemon-coloured with a brown navelring, but soon the lemoncolour changes into greyish yellow and a year afterwards the seeds are entirely yellowish-brown (pl. II, fig. 18);

4. "Bruine" (brown) from the moment of ripening yellowish brown on the whole seedcoat and a brown navelring (pl. II, fig. 25);

5. „Rotjes", a race characterised by a grey-brown seedcolour, that can be discerned in two types: a dark grey-brown (pl. II, fig. 23) and a less intense grey-brown type (pl. II, fig. 24);

6. "Zwarte" (black) with a pure black seedcoat (pl. II, fig. 16);

7. "Kievits" (lapwing) with a constant reddish violet marbling upon a yellowish groundcolour as racial character (pl. II, fig. 21).

Of course in the cultures from artificially obtained hybrids only, both parents were known with certainty; a great many spontaneous hybrids however showed in their posterities proportions of segregation, that were wholly parallel to those from artificial hybrids, and on this ground their descendance gave strong indi- 
cations for a certain race as being the fatherplant sought after. In these cases the results of spontaneous crosses are taken together with those of artificial hybrids.

\section{Cross of Gitroen $\times$ Wagenaar.}

The hybrid obtained between these two races showed the same phaenotype as the Wagenaar: brown navelring and soon colourchanging into brown of the remainder of the seedcoat were do. minant. Two families obtained from artificial crossings and one from a spontaneous hybrid came into cultivation; in all cases the Citroen-race was the mother. The segregations in the $F_{2}$ families gave the following numbers of frequency:

\begin{tabular}{r|c|c|c|c|c|c}
\hline Family & & Wagenaar-type & Citroen-type & Totals & $\begin{array}{c}\text { Proportion in } \\
\text { a total of 4 }\end{array}$ \\
\hline 997 & Artif. hybr. & 33 & 8 & 41 & $3.21: 0.79$ \\
1033 & Artif. hybr. & 25 & 9 & 34 & $2.99: 1.01$ \\
1034 & Spont. bybr. & 41 & 13 & 54 & $3.03: 0.97$ \\
\cline { 3 - 7 } & \multicolumn{1}{|c|}{ Total } & 99 & 30 & $\frac{129}{3.06: 0.94}$
\end{tabular}

The segregation follows in a sufficient way the scheme of a monohybrid; the difference between the two races depends upon the presence of a single factor in the Wagenaar, perhaps the same factor, as that indicated by Koolman as D.

\section{Cross of WagenaAR $\times$ Bruine.}

The yellowish brown colour of the "Bruine" showed to dominate over the yellow. Wagenar-seedcoat; the $F_{1}$-individuals could not be discerned from the brown race. Two $F_{2}$-families were grown: one originated from an artificial cross, made by Mr. C. J. DroogenDIJK, the other from a spontaneous hybrid, found as such in a culture of Wagenaar-beans. Some $\mathrm{F}_{3}$ families, that came from the firstmentioned $\mathrm{F}_{2}$ plant and showed the same segregation, may also be taken into consideration and tabulated together:

(Cf table page 111).

Three more $\mathrm{F}_{3}$-posterities, grown frown $\mathrm{F}_{2}$-individuals after artificial hybridization, contained only brownseeded plants $(34,23$ and 46); the two Wagenaar-like $F_{2}$-plants gave only Wagenaarseeded 


\begin{tabular}{|c|c|c|c|c|c|}
\hline \multicolumn{2}{|r|}{ Family } & Brown & Wagenaar & Total & $\begin{array}{l}\text { Proportion in } \\
\text { a total of } 4 \text { : }\end{array}$ \\
\hline \multicolumn{2}{|r|}{ Artif. hybr. $F_{z}$} & 8 & 2 & 10 & $3.20: 0.80$ \\
\hline \multirow[t]{5}{*}{1920.} & 763 & 33 & 9 & 42 & $3.14: 0.86$ \\
\hline & 764 & 38 & 10 & 48 & $3.17: 0.83$ \\
\hline & 767 & 61 & 26 & 87 & $2.80: 1.20$ \\
\hline & 768 & 33 & 12 & 45 & $2.93: 1.07$ \\
\hline & 769 & 35 & 8 & 43 & $325: 0.75$ \\
\hline \multicolumn{2}{|c|}{ 1921. 1038. Spont. hybr. $\mathrm{F}^{2}$} & 32 & 10 & 42 & $1.04: 0.96$ \\
\hline & & 240 & 77 & 317 & $3.02: 0.98$ \\
\hline
\end{tabular}

descendants (33 and 40) with one exception: a brownseeded plant, that was a new spontaneous hybrid.

The numerical proportions allow concluding to a monohybrid nature of the $F_{1}$; a single dominant factor being present in the brown race, absent in the Wagenaar, and probably the same factor as that, mentioned in my previous paper as $G$, perhaps also the same as Koolmans C.

\section{Cross Citronn $\times$ Bruine.}

In connection with the results, obtained in the two crosses above, the hybrid Citroen $\times$ Bruine was expected to be a dihybrid, segregating according to the scheme 12 brown: 3 wagenaar: 1 citroen, because of the epistasis, according to Koolman, of his factor $\mathrm{C}(\mathrm{G})$ for brown seedcoat and brown navelring over the factor $D$, that causes a brown colour in the navelring only. Individuals with $\mathrm{C}$ alone could not be discerned phaenotypically from the CD-plants. The segregation observed however gave other numerical proportions: in some cases the $F_{2}$ splitted in only two groups, viz. 3 brown: 1 lemoncoloured, while in others the three phaenotypical groups appeared indeed, but in numbers that deviate strongly from the expected $12: 3: 1$-proportion. These two groups may be separated in tabular form:

(Cf table page 112).

The monohybrid character of this segregation is beyond doubt; the brown race used in these crosses possessed only one factor that was absent in the lemoncoloured Citroen-individuals. 
112 SIRKS, THE COLOURFACTORS OF THE SEEdCOAT IN PHASEOLUS

Monohybrid segregation.

\begin{tabular}{rc|r|r|r|r}
\hline \hline Family & Brown. & Citroen, & Total. & Proportion in a total of 4. \\
\hline 990 & Artif. hybr. & 3 & 1 & 4 & $3.0: 1.0$ \\
1002 & $"$ & 30 & 7 & 37 & $3.24: 0.76$ \\
996 & Spont. hybr. & 10 & 3 & 13 & $3.08: 0.92$ \\
1003 & $"$ & 5 & 5 & 10 & $2: 2$ \\
\hline & & 48 & 16 & 64 & $3.0: 1.0$
\end{tabular}

Dihybrid segregation.

\begin{tabular}{|c|c|c|c|c|c|c|}
\hline \multicolumn{2}{|r|}{ Family } & Brown. & Wagenaar & Citroen & Total. & $\begin{array}{l}\text { Proportion in } \\
\text { total of } 16 .\end{array}$ \\
\hline 987 & Artif. hybr. & 20 & 4 & 10 & 34 & $9.41: 1.88: 4.71$ \\
\hline 991 & \multirow{2}{*}{ Spont. hybr. } & 9 & 2 & 3 & 14 & $10.28: 2.29: 3.43$ \\
\hline 9903 & & 20 & 10 & 8 & 38 & $8.42: 4.21: 3.37$ \\
\hline 999 & $"$ & 17 & 5 & 9 & 31 & $8.80: 2.58: 4.62$ \\
\hline \multirow[t]{2}{*}{1004} & $"$ & 14 & 4 & 3 & 21 & $10.67: 3.05: 2.28$ \\
\hline & Total & 80 & 25 & 33 & 138 & $9.28: 2.90: 3.82$ \\
\hline
\end{tabular}

The results are not at all in agreement with the expected proportion $12: 3: 1$; in all families the numbers of the groups are in defiance of this theoretical supposition. They come nearer to the scheme $9: 3: 4$ and induce thus to another hypothesis, that will be given below in connection with the results from other crosses.

\section{Cross of Citroen $\times$ Rotjes.}

As indicated above, the race known as "Rotjes" is not always uniform; darker and lighter types of greyish brown can in most cases be discerned. The colour can also come nearer to a reddish brown; besides individuals with a brown navelring, sometimes, though somewhat rarely, others without this racial character appear in cultures of this race. The cause of this mixture of types is for the greater part to be found in the difficulty of discerning them; if spontaneous hybridization has occurred, its results will in most cases remain unobserved, and the hybrids will find occasion to propagation and segregation, while in other races with 
light-coloured seedcoats these crosses are soon detected and may be removed. The grey colour, characteristic for the race "Rotjes" covers all other colours in a high degree, so that only a very sharp selection may discover the differences of types.

The cross Citroen $q \times$ Rotjes $d$ (greyish brown as in plate II Fig. 23) was cultivated in only one family; besides two spontaneous hybrids found in a culture of the lemoncoloured race, gave posterities of a wholly analogical composition. The $F_{1}$-individuals were of a reddish brown; the $F_{2}$-generations divided into 8 ; phaenotypically different groups: I dark redbrown, I a redbrown. (like $\mathrm{F}_{1}$ ), II dark greybrown, II a greybrown (all with a brown navelring), III greybrown with uncoloured or blue navelring, IV yellowbron as the brownseeded race „Bruine”, $V$ Wagenaar-type (yellow with brown navelring) and VI lemoncoloured Citroen-type: (without navelring). The types I, II and III are figured in pl. I. figs. 3,4 and 7 ; the remaining three agree entirely with fig. 25, 18 . and 22 of pl. II. Above those, still two plants with reddish brown seedcoat like that of the $F_{1}$ were selected from a culture of the Rotjes-race; they gave progenies segregating in the same way, so that as their father a plant of the Citroen-race may be indicated with a very high probability.

The frequency of the various types in $F_{2}$ may be found in the: following table:

\begin{tabular}{|c|c|c|c|c|c|c|c|c|c|c|c|c|c|}
\hline \multicolumn{5}{|c|}{ Type } & Ia & Ib & II a & II b & III & IV & $\mathbf{v}$ & IV & Tota \\
\hline \multicolumn{5}{|c|}{ 988. Artif hybr. } & 5 & 5 & 1 & 3 & 6 & 3 & $i$ & 2 & 26 \\
\hline 994. & Spor & aybr & rom & Citroen & 2 & 7 & 1 & 2 & 11 & 2 & 2 & 3 & 30 \\
\hline \multirow{2}{*}{$\begin{array}{l}1005 . \\
1006 .\end{array}$} & 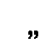 & $"$ & , & $"$ & 1 & 3 & - & 1 & 1 & 2 & - & 1 & 9. \\
\hline & ” & $"$ & " & Rotjes & 3 & 3 & - & - & 3 & 3 & 2 & 1 & 15 \\
\hline \multirow[t]{3}{*}{1015.} & $"$ & $n$ & " & $"$ & $\dot{0}$ & 11 & 2 & 4 & 2 & 2 & - & 5 & 32 \\
\hline & & & & & $\overline{17}$ & 29 & 4 & 10 & 23 & 12 & 5 & 12 & \multirow[t]{2}{*}{112} \\
\hline & & & & & \multicolumn{2}{|c|}{46} & \multicolumn{2}{|c|}{14} & 23 & $\overline{12}$ & 5 & 12 & \\
\hline
\end{tabular}

If the groups Ia with Ib and IIa with IIb are taken together, the segregation shows immediately to be a triheterozygotic: part of the individuals in the $\mathrm{F}_{2}$ possess the factor for grey (probably the $L$-factor, as indicated in my previous paper) while the remain- 
der is missing this factor; a part of them have a brown navelring (D) the others have not; some show the presence of the factor for a totally yellowish brown seedcoat $(G)$, in the others this factor is absent. Thus the $F_{1}$-individuals had as genotypic formula $\mathrm{G} \mathrm{g} \mathrm{D} \mathrm{d} \mathrm{L} 1$ and the $\mathrm{F}_{2}$-generations would thereby be composed of 8 types of individuals (when homozygotic or heterozygotic presence of a factor is supposed to give the same phaenotype): 1) $27 \mathrm{G} \mathrm{D} \mathrm{L}$, 2) $9 \mathrm{G} \mathrm{D} \mathrm{l,} \mathrm{3)} 9 \mathrm{G} \mathrm{d} \mathrm{L,} \mathrm{4)} 9 \mathrm{~g} \mathrm{D} \mathrm{L}$, 5) $3 \mathrm{G} \mathrm{d} \mathrm{1,}$ 6) $3 \mathrm{~g} \mathrm{D} \mathrm{l,} \mathrm{7)} 3 \mathrm{~g} \mathrm{~d} \mathrm{~L}$ and 8) $1 \mathrm{~g} \mathrm{~d} \mathrm{~L}$. On the supposition, that the three factors mentioned ( $G$ for the yellowish brown seedcoat, $D$ for the brown colour of the navelring, and $L$ for the grey colour) segregate independently from each other, the numbers observed in the $\mathrm{F}_{2}$-families give a very strong indication for the hypothesis, that the G-factor can become visible only if the D-factor is also present; in other cases the G-factor may be present but remains in cryptomeric (latent) position. If this may be supposed, the phaenotypes of group $1(27 / 64$ of the whole number) would be reddishbrown (type I), of group 2 yellowbrown (type IV), of groups 3 and 7 grey with uncoloured navelring (type III), group 4 grey-brown (type II), groups 5 and 8 lemoncoloured (type VI) and group 6 Wagenaar-type (type V).

A comparison of the numbers observed with the proportions that were expected on this hypothesis, may be given here:

\begin{tabular}{c|c|c|c|c|c|c}
\hline \hline Type & I & II & III & IV & V & VI \\
\hline Genotypes & G DL & G DL & G d L and g d L & G Dl & g D I & Gdl and g dl. \\
Theoret. & $27 / 64$ & $9 / 64$ & $9 / 64+3 / 64$ & $9 / 64$ & $8 / 64$ & $3{ }^{6} 4+I_{64}$ \\
proportion & & 15.75 & 21.0 & 15.75 & 5.25 & 7.0 \\
Expected & 47.25 & 15.75 & 23 & 12 & 5 & 12 \\
Observed & 46 & 14 & 25
\end{tabular}

The phaenotypic differences, by which group I a could be discerned from group I $b$, as also Il a from II $b$, have probably their ground in the incomplete dominance of the L-factor; if LLindividuals would show a darker intensity of colour than the heterozygous Ll-plants, this difference will be observable among the individuals of types I, II and III, so that these groups can be 
divided again in two parts $(1 / 3$ and $2 / 3$ ). In groups $I$ and II this division was tried with more or less result: I a contained $17, \mathrm{Ib}$ 29 individuals (theoretical $15.75: 31.5$ ), while II a with 4 and II b with 10 individuals come near to the expectation 5.25:10.5. In group III a further distinction of types was rather impossible.

5. Cross of Bruine $\times$ Rotjes.

Two families of artificially obtained hybrids between greybrown Rotjes and Bruine came into cultivation; two families originating from red-brown individuals found in a Rotjes-culture and showing a segregation parallel to that of the other plants, six families of artificial hybrids Bruine $\times$ Rotjes and eight families of redbrown spontaneous hybrids, found in a culture of the yellowbrown "Bruine". These $18 \quad \mathrm{~F}_{2}$-families could be classified in the same manner as those of the previous cross and gave so the following numbers of individuals per type:

\begin{tabular}{|c|c|c|c|c|c|c|c|c|c|c|c|c|c|}
\hline \multicolumn{3}{|c|}{ Family } & \multicolumn{2}{|c|}{ Type } & Ia & Ib & II a & II b & III & IV & $\mathbf{V}$ & VI & Total \\
\hline 1012 & Artif & hybr. fr & om 1 & Rotjes & 4 & 9 & 2 & 3 & - & 4 & 2 & - & 24 \\
\hline 1013 & " & - & y & $"$ & 3 & 7 & 3 & 5 & - & 4 & 1 & -1 & 23 \\
\hline 1014 & Spont. & hybr. & $"$ & " & 1 & 5 & 2 & 3 & - & 2 & - & $-i$ & 13 \\
\hline 1016 & " & $"$ & $"$ & , & 2 & 4 & 1 & 2 & - & 1 & - & - & 10 \\
\hline 1018 & Artif & hybr. fr & rom & Bruine & 2 & 4 & 2 & 1 & - & 4 & - & -1 & 13 \\
\hline 1019 & " & $"$ & $"$ & $"$ & 3 & 13 & 5 & 9 & - & 7 & 1 & $-i$ & 38 \\
\hline 1085 & , & $"$ & $"$ & $n$ & 4 & 7 & 1 & 6 & -1 & 11 & -1 & - & 29 \\
\hline 1086 & $"$ & $"$ & $"$ & $"$ & 6 & 14 & 2 & 1 & - & $4:$ & - & -1 & 27 \\
\hline 1087 & $"$ & $"$ & "r & $"$ & 2. & 9 & 3 & 1 & - & 4 & - & - & 19 \\
\hline 1100 & " & , & $"$ & " & 1 & .1 & - & - & - & 1 & - & - & 3 \\
\hline 1021 & Spont. & hybr. & $"$ & $n$ & 7 & 15 & 3 & 4 & - & 4 & 1 & -1 & 34 \\
\hline 1022 & $"$ & $"$ & " & " & 4 & 14 & 2 & 2 & - & 7 & 2 & - & 31 \\
\hline 1088 & " & $"$ & " & " & 3 & 3 & 1 & 3 & - & 5 & - & -1 & 15 \\
\hline 1089 & " & $"$ & $"$ & $"$ & 2 & 7 & 1 & - & - & 1 & 1 & -1 & 12 \\
\hline 1090 & " & $"$ & $"$ & $"$ & 3 & 9 & 1 & - & - & 2 & 3 & -1 & 18 \\
\hline 1103 & ” & $"$ & $"$ & " & - & 5 & 1 & 3 & - & 3 & 1 & - & 13 \\
\hline 1104 & " & $"$ & $"$ & $"$ & 2 & 1 & - & 1 & - & 1 & 1 & - & 5 \\
\hline \multirow[t]{3}{*}{1105} & $"$ & " & $n$ & " & 3 & 7 & 1 & 4 & - & 3 & - & - & 18 \\
\hline & & & & & 52 & 134 & 31 & 47 & - & 68 & 13 & & 345 \\
\hline & & & & & & 86 & 78 & & $-\mid$ & 68 & 13 & - & \\
\hline
\end{tabular}


Both types lacking the D-factor (III and VI) are absent; while the other types come very near to the proportions, that are expected according to the $9: 3: 3: 1-$ scheme of segregation. In a total number of 345 this expectation would be $1941 / 16: 6411 / 16: 6411 / 16$ : $219 / 16$; the numbers observed were $186: 78: 68: 13$. The division into groups I $a$ and I b, II $a$ and II $b$ however is here somewhat deviating from the expectation: the difficulty of discerning these types will be cause of this deviation.

The genotypic formula of the greybrown beans, called "Rotjes”, may thus be written in keeping with the results of the previous cross, as gg D D L L; that of the gellow-brown race „Bruine" is, here also G G D D 11 . The reddish brown hybrid is a diheterozygote $\mathrm{G} g \mathrm{D} \mathrm{D} \mathrm{L} 1$, and the $\mathrm{F}_{2}$-generation segregates into 9 G D L: 3 G D 1: 3 g D L: 1 g D 1.

In addition to these families, the segregation of which is entirely in harmony with the theoretical suppositions, in a culture of yellow-brown beans an individual was found with grey-brown seedcoats; its posterity (family 1027) showed a segregation into 4 individuals of type II and 2 of type V. It may be supposed that the mother of this spontaneously born hybrid was a Gg DD11heterozygote, that has given with a g $\mathrm{g} \mathrm{D} \mathrm{D} \mathrm{L} \mathrm{L-father} \mathrm{an} \mathrm{F}_{1}$-individual of the genotypic constitution g $\mathrm{g}$ D D L 1 . The motherplant had been lost and thereby its posterity could not be grown; a decision about its heterozygous nature being thus impossible.

6. OfFSPRING OF OTHER ABNORMAL PLANTS, FOUND IN „ROTJEs”.

Some other plants with abnormally coloured seedcoats, found in cultures of the race "Rotjes," gave as descendants four families, showing a segregation more or less parallel to those of the previous crosses. One of them had grey-brown seedcoats without the brown navelring, while the three others had reddish brown seedcoats. The segregations could be classified in the same groups as in the preceding cases:

(Cf Table page 117.)

The motherplant of family 992 with g $8 \mathrm{~d} \mathrm{~d} \mathrm{~L} 1$ as genotypic formula took thus its origin from two gametes $g \mathrm{~d} \mathrm{~L}$ and $\mathrm{g} \mathrm{d} \mathrm{l}$, either by spontaneous crossing of a phaenotypically identical g g d d L L with a lemoncoloured (g $g \mathrm{~d} d \mathrm{l}$ ) father, or as off- 


\begin{tabular}{l|c|c|c|c|c|c|c|c}
\hline \hline \multicolumn{1}{c|}{ Type } & I & II & III & IV & V & VI & Total & $\begin{array}{l}\text { Supposed } \\
\text { formula }\end{array}$ \\
\hline 992 greybrown without navelring & - & - & 26 & - & - & 7 & 33 & gg dd LI \\
1007 reddish brown & 11 & 2 & - & - & - & - & 13 & Gg DD LL \\
1008 reddish brown & 6 & 2 & 4 & - & - & - & 12 & Gg Dd LL \\
1009 reddish brown & 7 & 2 & - & - & - & - & 9 & GgDDLL
\end{tabular}

spring of a product of segregation after a previous; more complicated crossing. The family 1008 will have descended from a cross g g D D L L $\times$ G G d d L L, both greybrown parents (one with, the other without navelring) and the origin of families 1007 and 1009 may have been a cross between G G D D L L and g g D D L L. In every case, the results obtained are not in defiance of the suppositions given above.

\section{Cross of Citroen $\times$ Kievits.}

The so-called „Kievits”-race (kievit= lapwing), pl. II fig. 21 , is characterized by a reddish violet marbling on the seedcoat, that has a yellow-white groundcolour; this marbling however does not show any regularity in the distribution of the violet colour, as does the violet striping in other races; but it is a constant racial character like this, and may not be confounded with the inconstant, eversporting marbled lype. The other parent of these crosses was the lemoncoloured Citroen-race, mentioned above, with a yellow seedcoat without navelring (pl. II, fig. 22). By means of artificial crossing the hybrid was obtained in $3 \mathrm{~F}_{1}$ individuals (2 Citroen $q \times$ Kievits $\delta$ and 1 reciprocal). Besides two plants were found in a culture of the Kievits-race that showed to have a seedcoat identical with that of these $F_{1}$-plants and by their manner of segregation to have been born from a spontaneous crossing with Citroen as the father, and last two plants from the Citroen-Race that took their origin from a spontaneous fertilization by Kievits-pollen.

The seedcoat of these $F_{1}$-individuals (pl. I. Fig. 12) was reddish. violet marbled on a yellowbrown groundcolour. Anticipating the results of the next cross; it may te mentioned that these $F_{1}$-plants concerning their seedcoatcolours were phaenotypically: identical with those of the cross Bruine $\times$ Kievits, that will be treated below. The segregation in $\mathrm{F}_{2}$ was much more complicated than those 
given above; Type I had a more or less intense reddish violet marbling on a yellowbrown groundcolour as had the $F_{1}$-individuals; according to the prevailance of the violet or of the brown colour, this type has been divided further into five subtypes (I a-e); subtype Ic agrees with the $F_{1}$. Type II was selfcoloured yellowbrown; in some cases however the seedcoat had a violet glow upon the brown colour, so that two subtypes could be discerned: IIa yellowish-brown, and IIb the same with a violet glow. Type IIIa was the same as the well-known Wagenaar-race, while IIIb had the same seedcoat but with a violet glow. The plants, classified as type IV, had the same colours and the same pattern as the Kievits-race; as in type I here also the intensity of violet showed great differences between the various individuals, belonging to this group, so that a division in five subtypes was applied: pl. II fig. 19 shows a bean of the lightest of these subtypes, IVe. Types V, VI, VII and VIII were wholly without violet and without yellowbrown in their phenotypes: $V$ the lemoncoloured like the Citroenrace, VI yellow and white marbled (pl. II fig. 20), VII pure white and VIII a greyish white seedcoat, but possessing a brown navelring (pl. I fig. 10, probably identical with Koormans H-type). The indiduals of the seven $\mathrm{F}_{2}$-families, that were grown, were distributed over these various types in following frequencies:

(Cf table page 119)

At first sight these numbers may seem to be of little promise; if however the numbers of groups I, II, III a. s. o. are taken one for one, neglecting the further divisions Ia, Ib, Ic, a. s. o., a rather good numerical proportion can be found therein. There are types with and types without the brown navelring (factor $D$ ), types with and types. without the yellowbrown colour of the whole seedcoat (factor G), types with and types without the Kievits-pattern (violet marbling, that may provisionnally be ascribed to a factor $K$ ) and finally among the recessive lemoncoloured beans uniformly coloured and marbled individuals. This lastmentioned segregation may be explained rather sufficiently by the supposition of KooIman, that a chromogenic factor $B$ in homozygotic state causes an equal colouring, in heterozygotic presence however the inconstant type of marbling. It is however unclear, why this difference between 
VULGARIS L. AND IN -PH: MULTHFERUS WILLD.

\begin{tabular}{|c|c|c|c|}
\hline ๘ & เి $\infty$ 웡 & : & : \\
\hline$\overline{\bar{z}}$ & $\begin{array}{llllll}1 & 1 & 1 & 0 & 1 & 1\end{array}$ & N & $N$ \\
\hline 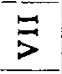 & $\tan \ln n$ & $\stackrel{\infty}{=}$ & $\stackrel{\infty}{\sim}$ \\
\hline 5 & $\infty$ la 1 -an & 10 & 10 \\
\hline$>$ & $+4 N-N+n$ & $\cong$ & $\cong$ \\
\hline 2 & $1|1| m \infty \mid$ & in & \\
\hline$\sum$ & $\mid N$ in $\mid N-1$ & 으 & \\
\hline$\sum$ & $1 \cdot 1111=\infty$ & m & लs \\
\hline$\sum$ & $=10 m 111$ & 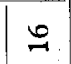 & \\
\hline$\sum^{\infty}$ & $\begin{array}{lllllll}m & 1 & 1 & 1 & 1 & 1 & 1\end{array}$ & $m$ & \\
\hline 总 & $\begin{array}{lllllll}-1 & \mid & N & 1 & 1 & 1 & -1\end{array}$ & + & \\
\hline$\stackrel{9}{\Xi}$ & $\pi \rightarrow \theta-n \rightarrow-$ & $=$ & T2 \\
\hline 㤩 & $1-1 n-n \mid$ & $\bullet$ & \\
\hline$\stackrel{\Xi}{=}$ & $0 \mathrm{~m}$ in $\mathrm{N}$. $\mathrm{men}$ & $m$ & m \\
\hline 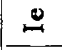 & $110 N \infty \ln \pi$ & $\underset{\sim}{\sim}$ & \\
\hline$\Xi$ & 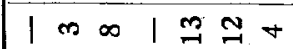 & P & \\
\hline 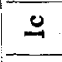 & $1101 \mathrm{mon}$ & $\cong$ & 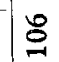 \\
\hline 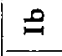 & $\vec{N} \sim \vec{N}=110$ & $\infty$ & \\
\hline$\stackrel{m}{m}$ & $1+1 \mid 1 \times 1$ & + & \\
\hline & 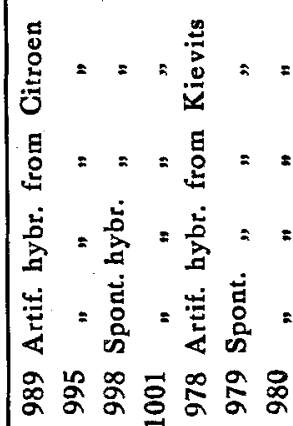 & & \\
\hline
\end{tabular}


$\mathrm{BB}$ and $\mathrm{Bb}$-individuals, that was observed by KooImAN also among the yellowbrown beans, could not be constated in my materials. If we indicate in his lines the groundfactor for pignientation as A, and if AA-plants without any other factor have white seedcoats, this complicated cross may be very well presented in a scheme of factorial constitutions. The formula of the Citroen-race may so, corresponding to thelsuppositions given above about the cryptomeric state of factor $G$, be written as A A B B G k kd, that of the Kievits-race as $A \mathrm{~A} \mathrm{~b} \mathrm{bg} \mathrm{g} \mathrm{KKDD}$ and the resulting $\mathrm{F}_{1}$-generation will thus be A ABbGgk d, a tetrahybrid that forms 16 different types of gametes: A B GKD, A B GKd, ABGkD, ABgKD, $A$ b GKD, $A B G k d, A B g K d, A b G K d, A B g k D, A b G k D$,

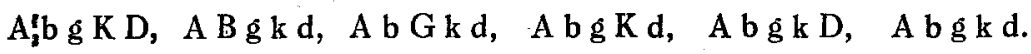
Consequently the $\mathrm{F}_{2}$-generation consists of 256 combinations. Supposed, that the factors $G, K$ and $D$ are entirely dominant, while the $B$ b-individuals can be discerned from the B B-plants only if the other factors are missing, and that the $K$-, as also the G-factor remains invisible, if $\mathrm{D}$ is absent, the following groups may be found among these 256 combinations:

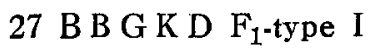

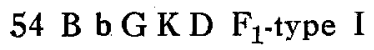

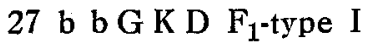

9 B B G K d lemoncoloured V

18 B b G K d lemon-marbled VI

9 b b G K d white VII

9 B B G k D yellowbrown II

18 B b G k D yellowbrown II

9 b b Gk D yellowbrown II

9 B B g K D kievits IV

$18 \mathrm{~B} \mathrm{~b} \mathrm{~g} \mathrm{~K} \mathrm{D} \mathrm{kievits} \mathrm{IV}$

9 b b g K D kievits IV
3 B B G k d lemoncoloured V

$6 \mathrm{~B} \mathrm{~b} \mathrm{Gk} \mathrm{d} \mathrm{lemonmarbled} \mathrm{VI}$

3 b b Gkd white VII

$3 \mathrm{~B} \mathrm{~B} \mathrm{~g} \mathrm{~K} \mathrm{~d} \mathrm{lemoncoloured} \mathrm{V}$

$6 \mathrm{~B} \mathrm{bg} \mathrm{K} \mathrm{d} \mathrm{lemonmarbled} \mathrm{VI}$

$3 \mathrm{~b}$ b g K d white VII

3 B B g k D wagenaar III

$6 \mathrm{~B} \mathrm{bgk} \mathrm{D}$ wagenaar III

3 b b g $\mathrm{D}$ white with brown navelring VIII

1 B B g k d lemoncoloured $\mathrm{V}$

$2 \mathrm{~B} \mathrm{~b} \mathrm{~g}$ k d lemonmarbled VI

$1 \mathrm{~b}$ b g k d white VII

In a total of 256 individuals of the $\mathrm{F}_{2}$-generation there are 108 
of phaenotype I, 36 of II, 9 of III, 36 of IV, 16 of V, 32 of VI, 16 of VII and 3 of VIII. In these proportions, one must keep in view the lack of difference between B B- and B b-plants in the types I, II, III, IV. A comparison of the numbers observed, with the proportions in a total of 269 , derived from these theoretical proportions, shows a rather good agreement between them:

\begin{tabular}{l|c|c|c|c|c|c|c|c||c}
\hline \multicolumn{1}{c|}{ Type } & I & II & III & IV & V & VI & VII & VIIr & Total \\
\hline Observed numbers & 106 & 39 & 15 & 37 & 17 & 35 & 18 & 2 & 269 \\
Theoretical proportions & 108 & 36 & 9 & 36 & 16 & 32 & 16 & 3 & 256 \\
Expectation & 113 & 38 & 9 & 38 & 17 & 34 & 17 & 3 & 269
\end{tabular}

Only type III, the Wagenaar-type has occurred in a number somewhat above the expectation, while type I has remained a little below; the deviations however are not strong enough to invalidate the theoretical suppositions. The more detailed divisions into types I a, I b a.s.o. don't allow till now more detailed suppositions; from groups I and IV a polymeric character of the factor for violet marbling could perhaps be concluded to, or from types II b and III $b$ the break of a linkage that existed before the crossing between a factor for violet and a factor for marbling (that are taken together in this paper as one factor $K$ ), but without further researches of the $F_{3}$-and following generations these suppositions are far from being justified.

In any case however this cross has shown with sufficient certainty: an independent segregation of the four factors $B, G, K$ and $D$;

a distinction between $\mathrm{BB}$ - and Bb-plants in the individuals that are missing other factors;

a cryptomeric state of $G$ - and $K$-factors, if the factor $D$ is absent.

\section{Cross of Bruine $\times$ Kievits.}

In treating the previous cross it was already mentioned, that in their seedcoats the $F_{1}$-individuals from the cross Citroen $\times$ Kievits are phaenotypically identical with those from Bruine $\times$ Kievits. Therefore the products of spontaneous hybridizations with the Kievits-race as mother cannot be determined immediately in so 
far it concerns the fatherplant: the segregations in $F_{2}$ of Bruine $\times$ Kievits however were of course less complicated, because of the presence of the $D$-factor in both these races, the $F_{1}$-individuals being thus homozygotes for this factor. In these segregations only types possessing the brown navelring (types I, II, III, IV and VIII) might occur, and from this the fatherplant could be identified as a yellowbrown individual in those cases also, that the father was unknown. Cultures were made of the descendants of three spontaneous and one artificial hybrid with the Kievits-race as mother and one spontaneous and two artificial hybrids that had the yellowbrown race as female parent.

The numbers of segregation may befound in the following table:

(Cf table page 123)

The results of these segregations are in rather good harmony with the hypotheses given above as being derived from the cross Citroen $X$ Kievits; the hybrid between Bruine and Kievits is a trihybrid A A B bGgKkD and its segregation will thus show the following groups :

9 B B G K D F $F_{1}$ type I

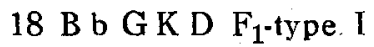

9 b.b GKD F $F_{1}$-type I

3 B B G k D yellowbrown II

6 B b k k yellowbrown II

3 b b Gk D yellowbrown II
3 B B g K D kievits-type IV

6 B b \& K D kievits-type IV

3 b b g K D kievits-type IV

1 B B g k D Wagenaar-type III

$1 \mathrm{~B} \mathrm{~b} g \mathrm{k}$ D Wagenaar-type III

$1 \mathrm{~b} b \mathrm{gkD}$ white with brown navelring VIII.

According to this scheme, in a total number of 64 individuals in $F_{2}$ there are belonging to type I 36 , II 12 , III 3, IV 12 and VIIl 1. The proportions derived therefrom for a total number of 175 may be compared with the observations in this way:

\begin{tabular}{l|c|c|c|c|c|c|c|c|c}
\hline \multicolumn{1}{c|}{ Type } & I & II & III & IV & V & VI & VII & VIII & Total \\
\hline Observed numbers"; & 92 & 43 & 11 & 28 & - & - & - & 1 & 175 \\
Theoretical proportions & 36 & 12 & 3 & 12 & - & - & - & 1 & 64 \\
Expectation & 98 & 33 & 8 & 33 & - & - & - & 3 & 175
\end{tabular}

This comparison of the results obtained with the numbers that 
VULGARIS L AND. IN PH. MULTIFLORUS WILLD.

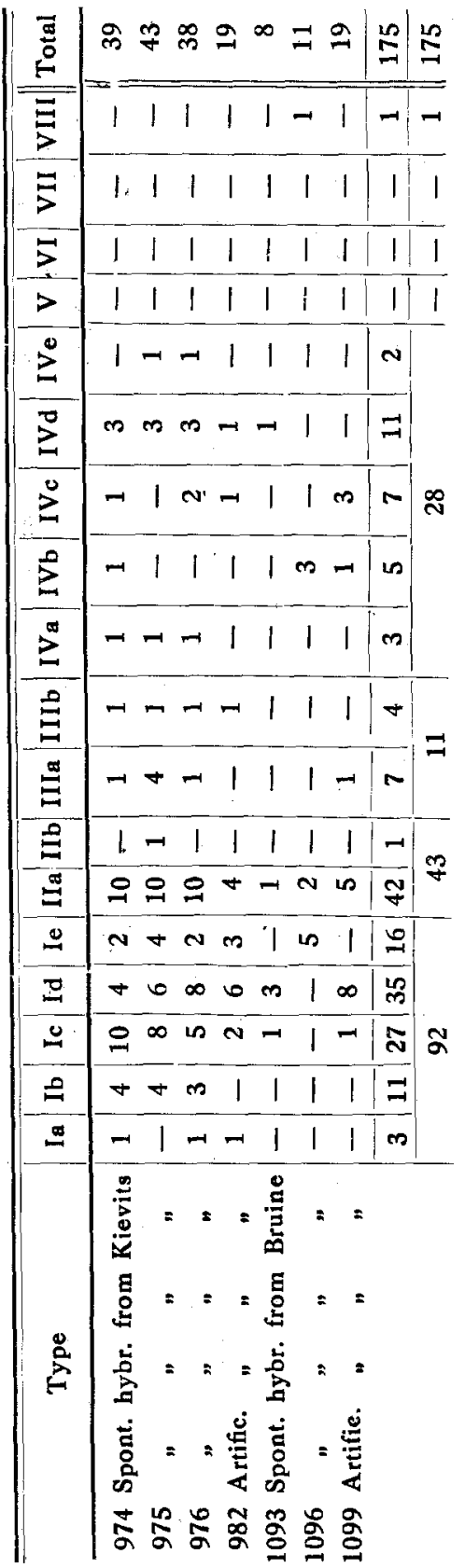


were theoretically expected, is a sufficient corroborative of the suppositions given above; the further details of types I and IV and the violet glow in types IIb and IIIb are, here also, still too complicated for allowing conclusions on their genotypic nature.

\section{Cross of Rotjes $\times$ Kievits.}

In a culture of the Rotjes-race two plants were found, the seeds of which were different from those of the other plants by a marbling of the grey-brown colour, and besides by a blueviolet marbling that covered here and there the greybrown groundcolour. Artificial hybrids between the Rotjes-race and Kievits were not available so that a decision could not be founded upon the phaenotype of the $F_{1}$-individuals, but the segregation of both $F_{2}$-families made the paternity of a redviolet-marbled individual (like the Kievits-race) very probable; in only one of them however the Kievits-race as such seems to have been the pollenparent, in the other a race with reddish-violet striped beans, as had the striped bushbean of Prague, used by TJebres and Kooman in their crosses.

The $\mathrm{F}_{2}$-posterity of the firstnamed spontaneous hybrid segregated into five well-discernable types, of which three again could be divided in subtypes: type I corresponded in phaenotype very well to the $\mathrm{F}_{1}$, some individuals however being darker of colouring (type Ia) than the others (Ib); type II was phaenotypically the same as the reddish-violet-marbled Kievits-race, the colour however being changed into blue-violet; here also two types of intensity could be discerned: one darker (IIa, plate II fig. 11) and the other, IIb, with a lighter and more matblue. The third type was apparently the same as the Kievits-race, and could again be divided into five subtypes (IIIa-e) according to the intensities of colouring: IV was identical with the grey-brown Rotjes-race, while $\mathrm{V}$ had the same phaenotype as the Wagenaar-race. The distribution of the individuals among these types, was the following:

\begin{tabular}{|c|c|c|c|c|c|c|c|c|c|c|c|c|c|}
\hline & Type & Ia & Ib & II & $I I b$ & $111 a$ & IIIb & III & IIId & IIIe & IV & $\mathrm{V}$ & Total \\
\hline \multirow[t]{2}{*}{1010} & $\begin{array}{l}\text { Spont. hybr. } \\
\text { from Rotjes }\end{array}$ & 3 & 23 & 7 & 8 & 1 & 3 & 2 & 2 & 4 & 9 & 5 & 67 \\
\hline & & 2 & & & 15 & & & 12 & & & 9 & 5 & 67 \\
\hline
\end{tabular}


Conclusions regarding the genotypical constitutions, that are realized in these phaenotypical groups, by which the segregation may be explained, are not at all easy because of the relatively little number of individuals. From the previous crosses however some suppositions have been derived, that may be justified here too: the Kievits-race would possess a factor $K$ responsable for the redvioletmarbling, while in it the factor $\mathrm{L}$ for grey-brown is absent; this Kievitsfactor does not occur in the Rotjes-race, but the L-factor is one of its characteristics. The segregation however shows to be more complicated than a dihybrid, for the K- and L-factors only are not sufficient for explaining the occurrence of phenotype II (blue-violet colouring). Probably the Rotjes-race is in possession of still anotber factor: $\mathrm{Bl}$, a factor that is changing the reddish violet into blue, and that remains invisible in the kotjes-race. This Bl-factor would be visible only, if reddish-violet is present and thus it cannot make its appearance in types IV and $V$, remains therein in a cryptomeric state. Now, if types with and those without $L$ are grouped, those with and those without Bl, those with and those without $K$, one would expect to find a $3: 1$ - segregation in each of these cases. The results dont agree with this expectation:

\begin{tabular}{c|c|c|c|c|c|c}
\hline \hline Type & $\begin{array}{c}\text { with L } \\
\text { I and IV }\end{array}$ & $\begin{array}{c}\text { without L } \\
\text { II, III and V }\end{array}$ & $\begin{array}{l}\text { with Bl } \\
\text { I and II }\end{array}$ & $\begin{array}{c}\text { without Bl } \\
\text { III }\end{array}$ & $\begin{array}{c}\text { with K } \\
\text { I, II and III }\end{array}$ & $\begin{array}{c}\text { without K } \\
\text { IV and V }\end{array}$ \\
\hline Number & 35 & 32 & 41 & 12 & 53 & 14
\end{tabular}

These numerical proportions may be considered as rather sufficient with regard to the factors $B 1$ and $K$ (expectation $40: 13$, resp. $50: 17$ ); those of the L-factor however show a considerable deviation from the expected $3: 1$-proportion, so that they lead to the conclusion, the $L$-factor must be in a cryptomeric state in some individuals. Probably this will be found to be the case in the bl-individuals, where thus the Bl-factor is missing, for the utterance of the Lfactor cannot be dependent upon the presence of the K-factor, because of its phaenotypical perceptibility in the Rotjes-race, where the $K$-factor is entirely absent. So the case will find a rather good explanation, if one supposes the Bl-factor to be cryptomeric in those beans, that are missing the $\mathrm{K}$-factor and the $\mathrm{L}$-factor as cryptomeric when the Bl-factor is absent. Type I will be represented than by the 
combination K L B l (27 from 64), type II contains K 1 B 1 (9 from 64), type III K L bl (9) and $\mathrm{KIbl}(3)$, type IV $\mathrm{kLBl}$ (9) and type $\mathrm{V}$ $\mathrm{k} \mathrm{L}$ bl (3), and $\mathrm{kl}$ bl (1). A comparison of the frequencies obtained with those expected according to these suppositions gives a rather good agreement:

\begin{tabular}{c|c|c|c|c|c|c}
\hline Type & I & II & III & IV & V & Total \\
\hline 1010 Observed frequencies & 26 & 15 & 12 & 9 & 5 & 67 \\
Theoretical proportions & 27 & 9 & 12 & 9 & 7 & 64 \\
Expected numbers. & 29 & 3 & 13 & 9 & 7 & 67
\end{tabular}

Type II is the only one, that does not wholly accord with the expectation; the cultures of $\mathrm{F}_{3}$-families that are grown in this year, will decide if these provisional suppositions are well-founded or if they are not; the meaning of the more detailed divisions of the types into subtypes may be kept also for further research.

The second of both spontaneous hybrids gave a more limited descendance; its examination gave therefore less results than the first one. Here also a grouping into five different types could be made; type I was divided into two subtypes: one darker Ia (pl. I fig. 5), the other lighter (pl. I fig. 6); type II was a blueviolet striped bean with a yellowish-white groundcolour (pl. I fig. 1); type III the same but the striping in reddish-violet (pl. I fig. 2), IV the Rotjesrace, and $V$ the Wagenaar-race. Type III may be supposed to be identical with the unknown father. The segregation observed in this

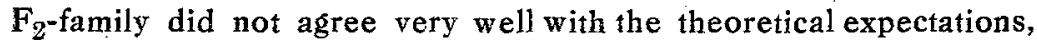
as is indicated by the following table:

\begin{tabular}{c|c|c|c|c|c|c}
\hline Type & I & II & III & IV & V & Total \\
\hline 1011 Observed frequencies & 3 & 9 & 5 & 3 & 2 & 22 \\
Theoretical proportions & 27 & 9 & 12 & 9 & 7 & 64 \\
Expected numbers. & 10 & 3 & 4 & 3 & 2 & 22
\end{tabular}

If here again the types with and those without one of the visible factors are taken together, the same phenomenon as that in the previous cross is met with: with $\mathrm{K}^{1}$ ( = the factor for violet striped pattern on the yellowish-white groundcolour), types I, II and III, 
there are 17, without $\mathrm{K}^{1}$ (IV and V) 5 individuals; with $\mathrm{Bl}$. (I, II) 12, without $\mathrm{Bl}$ (III) 5 plants; with L (I, IV) 6, without L. (II, III, V) 16 individuals. With regard to $K^{1}$ and $B l$ the segregations come very near the monohybrid 3:1-proportion; those for the L-factor are here also very deviating from the expected proportion. The cryptomeric state of the L-factor in those types, that do not possess the Bl-factor, is here the probable cause. But besides the deviation in types $I$ and II is highly remarkable; here the cause may perhaps been found in a possible coupling or repulsion between one of the factors $\mathrm{L}$ or $\mathrm{Bl}$ and the $\mathrm{K} 1$-factor. The cultures of this year will probably give certainty abcut this problematic factorial relation.

\section{Gross of Bruine $\times$ Zwarte.}

Only one $F_{1}$-plant of this hybrid was available; its seedcoats were intense black. The $\mathrm{F}_{2}$-family segregated very simply into three groups: I black (39 individuals), II reddish-brown (phaenotypically identical with the $F_{1}$ of cross 4 , Citroen $\times$ Rotjes ; 6 individuals) and III yellowish brown, as the common yellow-brown race „Bruine” (3 plants). The hybrid did not segregate further than the yellowbrown type; it may thus be concluded, that the G-factor was present in both parents. Besides this one, the black parent seems to have possessed the $L$-factor and a factor $Z$, that is responsible for the black colouring. The hybrid has been GG Ll $\mathrm{Zz}$ and segregates thus into $9 \mathrm{GLZ}, 3 \mathrm{GlZ}, 3 \mathrm{GLz}$ and $1 \mathrm{Glz}$; giving so 12 blacks: 3 reddish-brown: 1 yellow-brown, and this is in good accordance with the numbers observed:

\begin{tabular}{c|c|c|c||c|c}
\hline Type & I & II & III & Total & Remark \\
\hline 1028 Observed frequencies & 39 & 6 & 3 & 48 & $\begin{array}{c}\text { Among the 39 blackseeded indivi. } \\
\text { duals there were 4, that had besides }\end{array}$ \\
Theoretical proportions & 12 & 3 & 1 & 16 & $\begin{array}{l}\text { black, also reddish.brown beans; } \\
\text { their classification in type Imay thus } \\
\text { be doubtful. }\end{array}$
\end{tabular}

\section{Cross of Kievits $\times$ Zwarte.}

In a culture of the Kievits-race, one spontaneous hybrid was found with blackmarbled pattern upon a greyish white groundcolour. The $\mathrm{F}_{2}$ generation of this hybrid consisted of $\mathbf{5 3}$ individuals, all coloured, so that the supposition: the unknown father was a white bean, may be con- 
sidered to be very feeble. Most probably a blackseeded bean had functioned as pollenparent; the segregation fell into 11 phaenotypical groups :

977 I black marbling upon greyish white groundcolour (28 individuals);

II matblue marbling upon greyish white groundcolour (1 ind.);

III darkblueviolet marbling upon yellowish white groundcolour (1 ind.);

IV matblueviolet marbling upon yellowish white groundcolour (1 ind.);

$\mathrm{V}$ greyish brown marbled, here and there somewhat violet (3 ind.);

VI reddish brown marbled, here and there somewhat violet ( 1 ind.);

VII red marbling, here and there somewhat violet (2 ind.);

VIII yellowish brown marbling, here and there somewhat violet ( 2 ind.);

IX selfcoloured black ( 9 ind.);

$X$ reddish brown selfcoloured ( 1 ind.);

XI Wagenaar-type ( 1 ind.);

Such a complicated segregation with very little groupnumbers does not allow a detailed analysis of the factorial constitutions, if, as is here the case, only one $F_{2}$-family is available; the $F_{3}$-cultures in this year will perhaps give the possibility of a decision. The results given above however are sufficient for argumenting a provisional hypothesis about the genotypic factors that are present in the parents and in the hybrid. There are types possessing the factor for black, $Z$, and other types without this factor; there are types with $L$, the factor for grey-brown and types missing this one; there are types with $G$, the factor yellow-brown and types, where this factor is failing and last types with $K$, the factor for Kievits-pattern besides types without $\mathrm{K}$. The probable genotypic constitution of the Kievits-race can thus be supposed to be $\mathrm{g} g 11$ bl. bl. $z \mathrm{zKK}$, while the black race had, in harmony with the suppositions in the foregoing cross G GLLBl. Bl. ZZ k k as genotypic formula. The segregation will thus be that of a pentaheterozygote and cannot be studied in detail in the few materials till now arailable. In some respects the numerical proportions are 
clear enough; four groups may be found that are rather good in accordance with a 9:3:3:1-segregation: blackmarbled, blackunicoloured, no-black-marbled; no-blackunicoloured are represented by $28: 14: 9: 2$ individuals, while a segregation according to $9: 3: 3: 1$ would give as expectation $30: 10: 10: 3$ in a total of 53 . It seems however to be useless to go further into details about such conclusions, before more materials are available.

\section{2a. Gross of Bruine $\times$ Witte.}

Four $F_{1}$-plants were obtained by artificial hybridization: one from the white-seeded plant as mother, three from the brown race as seedparent. Besides four spontaneous hybrids were found in a culture of white-seeded plants and five others from a culture of the brown race, and recognised from their manner of segregation to have been born as hybrids with white as pollenporent. Those, in total thus thirteen, $F_{1}$-plants showed not only to have the same phaenotype, but also they segregated in their $\mathrm{F}_{2}$-generations in one and the same manner, giving the same phaenotypically distinctive groups, so that the genotypical identity of the $F_{1}$-individuals might be concluded to with rather great probability. The segregation resulted into the occurrence of nine phaenotypes: the first, I, had the same seedcoatpattern as the $F_{1}$-individuals, blackmarbled upon a yellowbrown ground-colour (pl. II. fig. 13); II had a reddish brown marbling upon yellowish brown; III had a grey-brown marbling upon a greyish white ground (pl. II. fig. 14), IV was yellow-brownmarbled upon a light yellow groundcolour (pl. II fig. 15); as parallels to these four groups could be considered four others: V selfcoloured black (fig. 16), VI selfcoloured redbrown, VII selfcoloured grey-brown (fig. 17) and VII selfcoloured yellow-brown; as last a group (IX) of whiteseeded plants without coloured navelring.

The distribution of the descendants among these nine groups. results from the table given below; the good harmony between the theoretical suppositions and of the proportion observed of coloured: white $(279: 87$ with an expectation of $275: 91)$ is striking immediately. All white parents seem to have been of an aa-constitution and from this absence of the A-factor to have derived their white colour; relative to their other genotypic factors, nothing can be said. Therefore, if the little numbers of each family allow a con-

Genetica IV. 
clusion, one might suppose the genotypical identity of the white parents in their whole genotypic constitution, because of the parallelism between the various segregations, that have shown all the same scheme:

\begin{tabular}{|c|c|c|c|c|c|c|c|c|c|c|c|c|c|c|}
\hline \multicolumn{5}{|c|}{ Type } & $I$ & II & III & IV & V & VI & VII & VIII & IX & Total \\
\hline & Artif. & hybrid & from & Witte & 7 & 1 & 1 & 3 & 5 & 2 & 4 & 2 & 6 & 31 \\
\hline 983 & Spont & hybrid & fron & Witte & 9 & 2 & -1 & 1 & 3 & $1-$ & 2 & 3 & 5 & 25 \\
\hline 984 & " & $"$ & $"$ & $"$ & 19 & 5 & - & - & 7 & 2 & 3 & - & 15 & 51 \\
\hline 985 & $"$ & 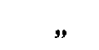 & $"$ & $"$ & 10 & - & 4 & 5 & 8 & 1 & 6 & 2 & 8 & 44 \\
\hline 986 & $"$ & $"$ & $"$ & " & 7 & 4 & - & 2 & 3 & 1 & 5 & 4 & 12 & 38 \\
\hline 1020 & Artif. & bybrid & from & Bruine & 1 & 2 & - & -1 & 1 & 1 & 1 & - & 3 & 9 \\
\hline 1024 & $"$ & $"$ & " & $"$ & 1 & 1 & - & - & - & - & 1 & - & 1 & 4 \\
\hline 1025 & $"$ & " & $"$ & " & 4 & 3 & 1 & 1 & 2 & - & - & - & - & 11 \\
\hline 1029 & Spont & hybrid & from & Bruine & 23 & 4 & 4 & 3 & 19 & 9 & 7 & 11 & 30 & 110 \\
\hline 1094 & " & " & " & $"$ & 1 & 1 & - & - & 2 & 2 & - & 3 & 3 & 12 \\
\hline 1097 & $"$ & " & 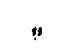 & \# & 4 & 1 & - & - & 1 & - & 3 & - & 2 & 12 \\
\hline 1098 & $"$ & $n$ & $n$ & $"$ & 8 & - & - & - & - & - & 1 & - & - & 10 \\
\hline \multirow[t]{3}{*}{1102} & " & $"$ & $"$ & " & 3 & - & - & - & 4 & - & - & - & 2 & 9 \\
\hline & & & & & 97 & 24 & 10 & 17 & 55 & 18 & 33 & 25 & 87 & 366 \\
\hline & & & & & & \multicolumn{3}{|c|}{148} & \multicolumn{4}{|c|}{131} & 87 & 366 \\
\hline
\end{tabular}

Though these numerical proportions do not meet in details the theoretical suppositions given above, there are certain conclusions, that may be drawn from these segregations. The $F_{1}$-plants may be considered to have been heterozygotes in five genotypic factors: A (groundfactor for pigmentation), D (factor for coloured navelring), G (yellow-brown colour of the seedcoat), L (grey-brown seedcoat) and $Z$ (black seedcoat). Probably they were also heterozygotes in the factor $B$, that causes according to Koolman in heterozygotic state the eversporting marbled pattern. In every case the segregation is in perfect accordance with the classical proportion $6: 6: 4$, mentioned above, because of the numbers observed to be 148 marbled: 131 selfcoloured: 87 whites (expected in a total of $366: 1371 / 4 \mathrm{~m}: 1371 / 4 \mathrm{~s}: 911 / 2$ w.). The absence of yellowish brown plants however (not only marbled, but also selfcoloured) in the rather comprehensive family 984 indicates with some probability that its $F_{1}$-plant was a homozygote in respect to the L-factor, so that the fatherplant seems to have been not a yellow-brown, but a 
red-brown (Rotjes)-plant. The segregation of white-seeded aaplants results from the heterozygotic state of the A-factor; the $D$-factor, that is visible more or less in all coloured individuals, is missing entirely in these white-seeded descendants, so that no one individual of the so-called H-type has occured. Therefrom one might conclude to a linkage of very high degree between the factors $A$ and D; all aa-plants were also dd, while all AA-plants, insofar one could discern it phaenotypically, possessed the coloured navelring $D$. The conclusion of the heterozygotic state of the Gfactor might perhaps be met with some doubt, because of the segregation going not tarther than the yellow-brown type; the previous crosses however have led to the genotypic formula g g L L for beans of the grey-brown type (like the Rotjes-race) and the occurrence of such grey-brown descendants in these $F_{2}$-families can only be explained by supposing a heterzygotic state of the G-factor.

Tschermak already had found a difference in proportions of colourypes between the marbled beans and the selfcoloured ones; the numbers given above seem to show the same. Here also, as in Tschermaks researches, the blackselfcoloured beans are too few in number in relation to the numbers of grey-brown and yellowbrown types; among the marbled groups these proportions seem to have been reversed. The further study of the $F_{3}$-families will give more confirmed conclusions.

\section{2b. Cross of Bruine $\times$ Witte?}

Besides the black-yellow-brown marbled $F_{1}$-plants, the posterities of which gave entirely parallel segregations, one plant, originated as spontaneous hybrid in a culture of "Bruine" and showing the same phaenotype as the others, segregated in $F_{2}$ in another way, especially regarding the little number of white-seeded descendants. The distribution of its $\mathrm{F}_{2}$-descendants among the same phaenotypes as in the previous crossings was found to be as follows:

\begin{tabular}{c|c|c|c|c|c|c|c|c|c|c|c}
\hline Type & I & II & III & IV & V & VI & VII & VIII & IX & Total \\
\hline 1023 Spont. hybrid from Bruine & 11 & 4 & - & - & 8 & 2 & 7 & 5 & 3 & 40
\end{tabular}


If truly the pollenparent in this case has been a white-seeded individual, this white-seeded plant will probably have been an A-individual, that missed all other colourfactors or in which all other colourfactors were in a kryptomeric state. The formula of the hybrid will perhaps have been A AB bGgL1Zz; a further research of the $F_{3}$-families will give here the correct explanation.

12c. Gross of Bruine $\times$ Witte.

The black-yellow-brown marbled pheenotype is of course not the only one, that can take its origin after the cross Bruine $\times$ Witte. Other spontaneous crossings were found, though in remarkable less numbers. So for example reddish brown-yellowbrown marbled individuals; their segregation was of course less complicated than that of the blackmarbled $F_{1}$-plants. Five phaenotypical groups only were observed in these segregations: I redbrown marbled, II yellow-brown-marbled, III redbrown selfcoloured, IV yellow-brown selfcoloured and $\mathrm{V}$ white. The frequencies of these groups in the $\mathrm{F}_{2}$-generations that were grown and in some $\mathrm{F}_{3}$-families, that were the posterities of redbrown marbled $\mathrm{F}_{2}$-individuals, coming from a cross Bruine $\times$ Witte, and segregating along the same lines, are tabulated in the following table:

\begin{tabular}{|c|c|c|c|c|c|c|c|c|c|c|c|}
\hline \multicolumn{6}{|c|}{ Type } & I & II & III & IV & $\mathbf{V}$ & Total \\
\hline \multicolumn{6}{|c|}{1044 Spont. hybr. from Bruine } & 8 & 2 & 11 & 4 & 7 & 32 \\
\hline \multirow{2}{*}{$\begin{array}{l}1047 \\
1048\end{array}$} & " & $"$ & & $n$ & & 4 & 1 & 6 & 1 & 5 & 17 \\
\hline & $\mathrm{F}_{3}$ after & spont. & hybr. & from & Bruine & 20 & 7 & 19 & 6 & 19 & 71 \\
\hline \multirow{3}{*}{$\begin{array}{l}1049 \\
1050\end{array}$} & $"$ & $"$ & " & , & " & 11 & 4 & 18 & 5 & 11 & 49 \\
\hline & $n \quad \cdots$ & $n$ & $n$ & " & $"$ & 18 & 7 & 14 & 4 & 12 & 55 \\
\hline & & & & & & 61 & 21 & 68 & 20 & 54 & 224 \\
\hline
\end{tabular}

Other $\mathrm{F}_{3}$-families, derived from redbrown marbled $\mathrm{F}_{2}$-plants segregated in still less phaenotypical groups; these may also be given here in a table:

\section{Cf table page 133}

The whole segregation indicates a trihybrid nature of the $F_{1}$-plants, the formula of which can be written as $A$ a B bGGL1; its descendants segregate thus in five phaenotypical groups: I A B b GL, II ABbG I, III A B B (or b b) GL, IV A B B (or b b) G1 and V white a-plants. 


\begin{tabular}{|c|c|c|c|c|c|c|c|c|}
\hline & Type & I & II & III & IV & $\mathrm{V}$ & Total & $\begin{array}{l}\text { Probable genotype } \\
\text { of the } F_{2} \text {-plant }\end{array}$ \\
\hline 1045 & $F_{\hat{B}}$-family & 6 & - & 9 & - & 5 & 20 & $A$ a $B$ b GG L L \\
\hline 1046 & $"$ & 11 & - & 14 & - & - & 25 & A A B b G G L L \\
\hline 1053 & " & 15 & 3 & 17 & 7 & - & 42 & A A B b G G L 1 \\
\hline 1054 & " & 12 & 5 & 16 & 3 & - & 36 & $A$ A B bGGLl \\
\hline 1057 & " & 18 & - & 21 & - & 12 & 51 & $A$ a $B$ bGGLL \\
\hline
\end{tabular}

The $F_{3}$-families 1048,1049 and 1050 are descendants from plants with $A$ a B bGGL 1 as genotypic formula; the Families 1045 and 1057 from A a B b G G L L-individuals, 1046 from an A A B b G GLLplant, while 1053 and 1054 have had an A A B bGLL l-individual as ancestor.

12d. Cross of Bruine $\times$ Witte.

A third phaenotype was also found in a culture of Bruine as spontaneous hybrid from a white seeded pollenparent: a plant with yellow-brown-marbled seeds, identical with the phaenotype of group II in the previous crosses. In the same manner as the $F_{2}$, raised from this $F_{1}$-plant, some other $F_{3}$ posterities, grown from the yellow-brown-marbled $\mathrm{F}_{2}$-individuals mentioned under $12 c$, segregated into 6 yellow-brownmarbled : 6 yellow-brown selfcoloured $: 4$ white. For the numbers of segregation were in these cases: $8: 5: 3 ; 12: 14: 9 ; 21: 19: 14 ; 9: 11: 5$ and $26: 22: 17$, or as totals $76: 73: 48$, being expected the proportions of $737 / 8: 737 / 8: 4914$. This spontaneous hybrid, as also the $F_{2}$-plants in the foregoing cross had the genotypic formula of $A$ a B bGG and segregated into $6 \mathrm{AB} \mathrm{b} \mathrm{G:6} \mathrm{A} \mathrm{B} \mathrm{B} \mathrm{(or} \mathrm{b} \mathrm{b)} \mathrm{G}$ and 4 a-plants.

\section{Cross of Gitroen $\times$ Witte?}

As last cross among Phaseolus vulgaris a spontaneous hybrid may be mentioned, found in a culture of the Citroen-race, that gave a segregation somewhat parallel with those of the hybrids, treated under $12 b$. The red-brown and yellow-brown types are missing here entirely; in other directions the hybrid however shows a more detailed segregation. The $F_{1}$-plant had greyish black-marbled seeds with a greyish-white groundcolour (pl. I fig. 9) and segregated in $F_{2}$ into eight phaenotypical groups. I was identical with the $F_{1}$-type; 
II was grey-marbled upon white; III greyish black selfcoloured; IV grey selfcoloured, $\mathrm{V}$ H.type (white with brown navelring); VI Wagenaar-type, VII lemoncoloured and VIII white. The frequencies in $\mathrm{F}_{2}$ were as follows:

\begin{tabular}{c|c|c|c|c|c|c|c|c|c}
\hline Type & I & II & III & IV & V & VI & VII & VIII & Total \\
\hline 1000 Spont. hybr. from Citroen & 10 & 4 & 5 & 2 & 5 & 1 & 1 & 1 & 29
\end{tabular}

If here the same blackfactor $Z$ has played a rôle, as in the previous crosses, one might conclude, that it gives the phaenotype of bright black only when the factor for yellowbrown, G, is also present; if this factor is absent, the Z-factor will give only a greyishblack colour. Further conclusions may be reserved for the future.

\section{b. Phaseolus multiflorus.}

The scarletrunnerbean is in many respects less favourable for a genotypic analysis of its varieties than the races of the common gardenbean; first in individual cultures the plant requires a stalk and a square metre each, and second the cross-fertilization in this species is certainly more important than in the other, so that isolation of the inflorescences seems to be a necessary condition for obtaining exact results. This isolation however is very difficult and has given in my researches in a few cases only some seeds, but never more than four in a whole inflorescence. Obtaining of reliable numbers in these researches is thus much less probable than in those concerning Phaseolus vulgaris.

The number of varielies in this species is only a few; the most common form with red flowers has blackmarbled seeds upon a light-violet ground (pl. III fig. 2); besides there are redflowering forms with black marbling and a darkviolet groundcolour (fig. 3), redflowering ones with light-violet colour and here and there little black spots (fig. 4), redflowering plants with shining black seeds (fig. 5), a red-and-white flowering (socalled Papillon) type with yellow-white and brown-marbled seeds (fig. 6), red-and-white flowering with yellowish-white and grey-marbled seeds (fig. 7) and last a whiteflowering race with pure white seeds (fig. 1), wbich race is used on a great scale as vegetable in our country. The redflowering 

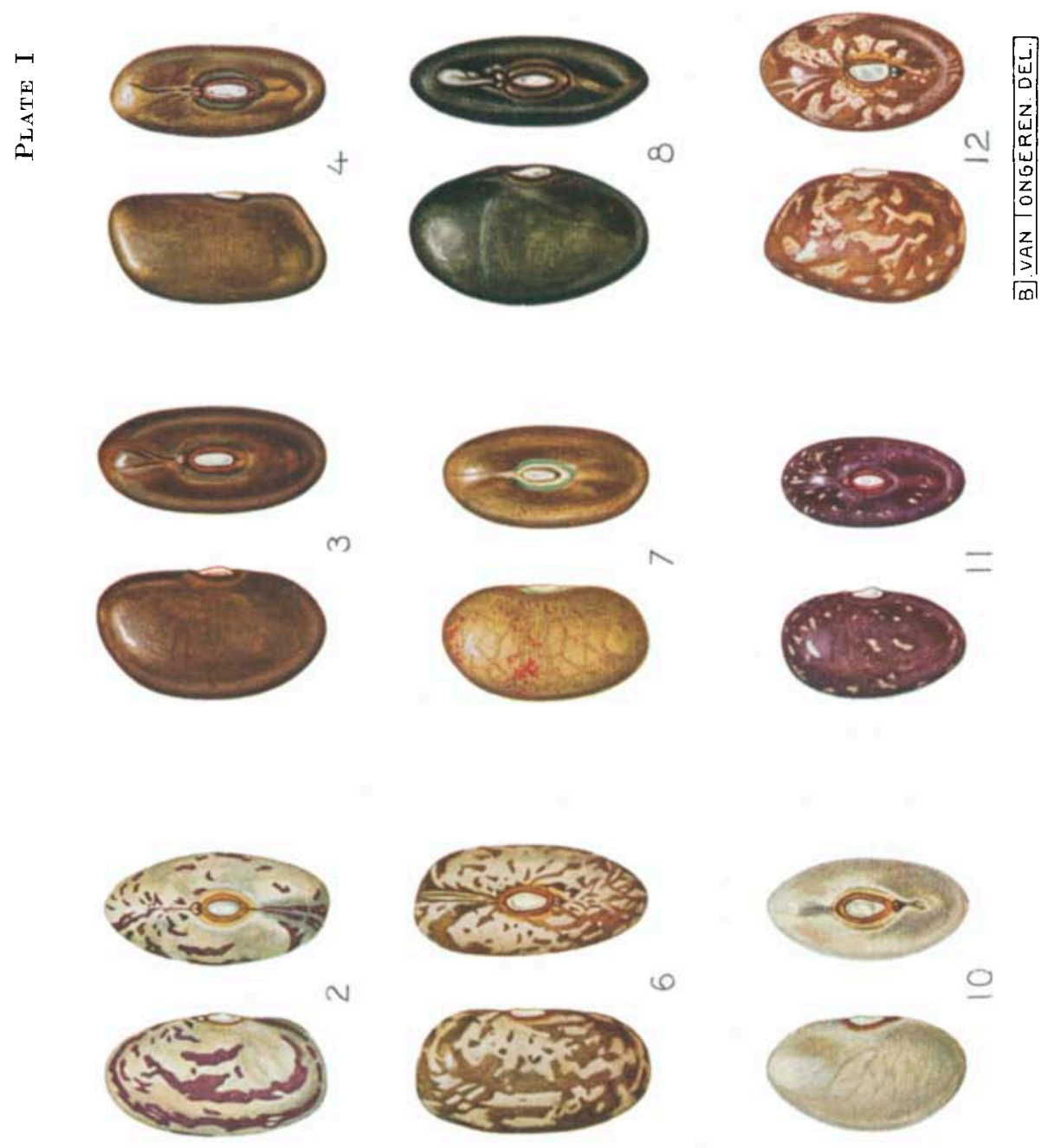

0

으
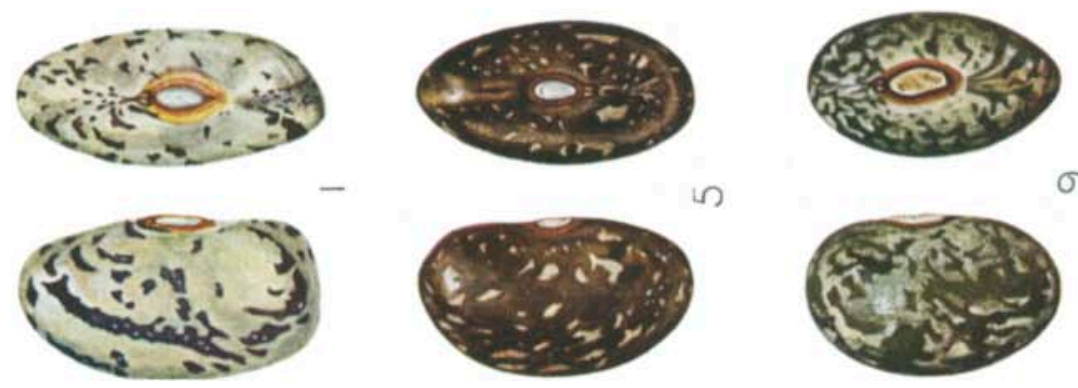

ก

の)
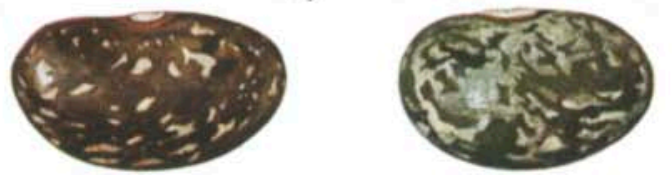
and red-and-white ones are used more as ornamental plants.

The whiteseeded race was cultivated during four years (19181921) always in the neighbourhood of redflowering individuals; it has given however never coloured descendants; artificial hybridizations though made on a rather great scale, have never yielded any result.

The redflowering race, obtained as such from a seedgrower, has shown from the beginning a rather important multiformity; in the first year of cultivation already the types $2,3,4$ and 5 could be discerned. In later years plants of types 6 and 7 were obtained. The posterities of these plants have for the greater part shown to be constant; some of them however segregated into more types. These segregations are given in the following table:

\begin{tabular}{|c|c|c|c|c|c|c|c|c|}
\hline \multirow[t]{2}{*}{ Type of motherplant: } & \multicolumn{7}{|c|}{ Type of descendants. } & \multirow[b]{2}{*}{ Total } \\
\hline & 1 & 2 & $\mathbf{3}$ & 4 & 5 & 6 & 7 & \\
\hline 1. White & 42 & - & - & - & - & - & - & 42 \\
\hline " & 20 & - & 一 & - & - & - & - & 20 \\
\hline$"$ & 31 & - & - & - & - & - & - & 31 \\
\hline 2. Lightviolet marbled & - & 27 & - & - & - & 7 & - & 34 \\
\hline ” & 2 & 12 & - & - & $\left.11^{1}\right)$ & - & - & 25 \\
\hline$"$ & 3 & 52 & - & - & $\left.2^{1}\right)$ & - & - & 57 \\
\hline$"$ & - & 73 & $\left.4^{1}\right)$ & - & 3) & - & - & 80 \\
\hline ” & - & 56 & $\left.1^{1}\right)$ & - & $\left.8^{1}\right)$ & - & - & 65 \\
\hline$"$ & 10 & 45 & $\left.7^{1}\right)$ & - & $\left.14^{1}\right)$ & - & - & 76 \\
\hline , & 8 & 59 & - & - & $\left.9^{1}\right)$ & - & - & 76 \\
\hline " & - & 45 & - & $\left.3^{1}\right)$ & - & - & 一 & 48 \\
\hline 3. Darkviolet marbled & - & 9 & 21 & - & - & - & - & 30 \\
\hline$"$ & - & 16 & 59 & - & $\left.3^{1}\right)$ & - & $\mp$ & 78 \\
\hline 4. Lightviolet spotted & - & 9 & - & 21 & - & - & - & 30 \\
\hline$"$ & - & 17 & - & 44 & $\left.1^{1}\right)$ & - & - & 62 \\
\hline 5. Black & - & 7 & - & - & 23 & - & - & 30 \\
\hline$"$ & - & 9 & - & - & 31 & - & - & 40 \\
\hline$"$ & - & 18 & - & - & 60 & - & - & .78 \\
\hline " & 4 & 14 & - & - & 47 & - & - & 65 \\
\hline$"$ & 17 & 15 & - & 一 & 43 & - & - & 75 \\
\hline 6. Brown-white marbled & - & $\left.6^{1}\right)$ & - & - & - & 10 & 3 & 19 \\
\hline
\end{tabular}

1) = probably new spontaneous hybrids, 
136 SIRKS, THE COLOURFACTORS OF THE SEEDCOAT IN PHASEOLUS

Though these numerical proportions are not entirely proving, they seem to indicate the correctness of following conclusions:

1. White is the recessive form, that is missing a groundfactor for pigment;

2. Lightviolet-marbled plants do segregate white descendants; the monohybrid nature of this segregation, however, is uncertain (168: 23);

3. Darkviolet-marbling dominates lightviolet marbling; the difference is caused by only one factor $(80: 25)$;

4. The spotted type dominates the lightviolet marbling, as may be concluded from the segregation 63 spotted: 26 lightviolet marbled;

5. Black is dominant over lightvioletmarbled, as also over white seedcoat; 204 blacks: 63 lightvioletmarbled; one of the segregations seems to segregate into 12 black: 3 lightvioletmarbled: 1 white, the other into $9: 3: 4$;

6. Brownmarbling (Papillonpattern) is recessive to lightviolet marbling $(27: 7)$; besides an absolute linkage be mentioned between this pattern of the seedcoat and the red-and-white colour of the flower (these characteristics may also be considered as to be caused by one pleiotropic factor);

7. The brown papillonpattern is dominant over the grey-white marbling (segregation $10: 3$ ). 

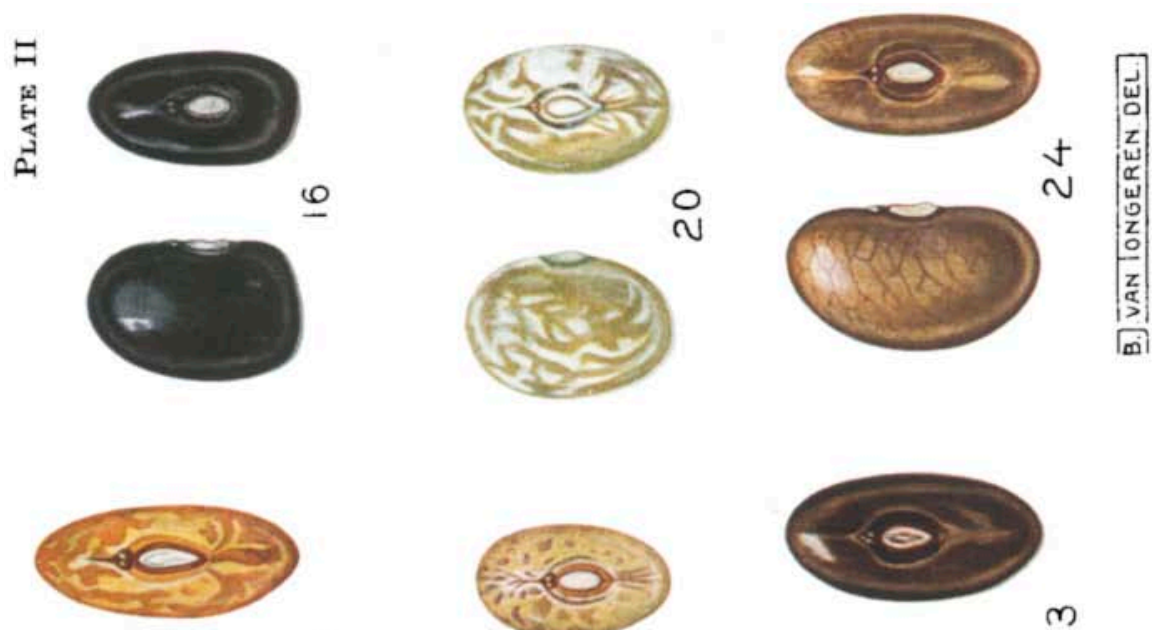

1
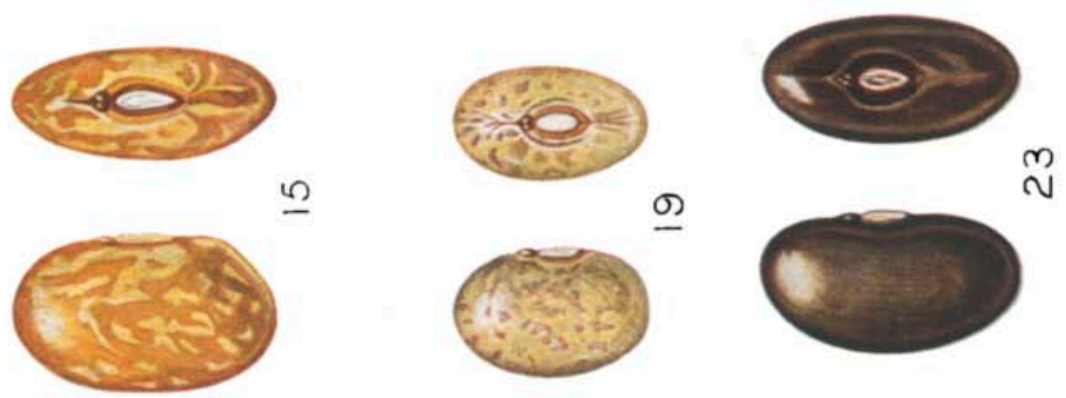

으
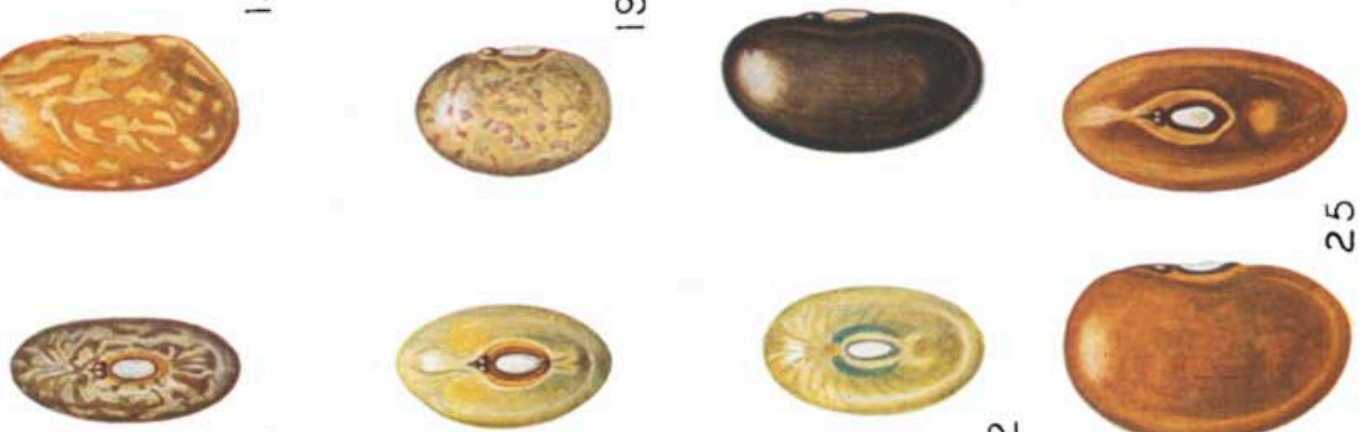

$\pm$

$\underline{-}$

N
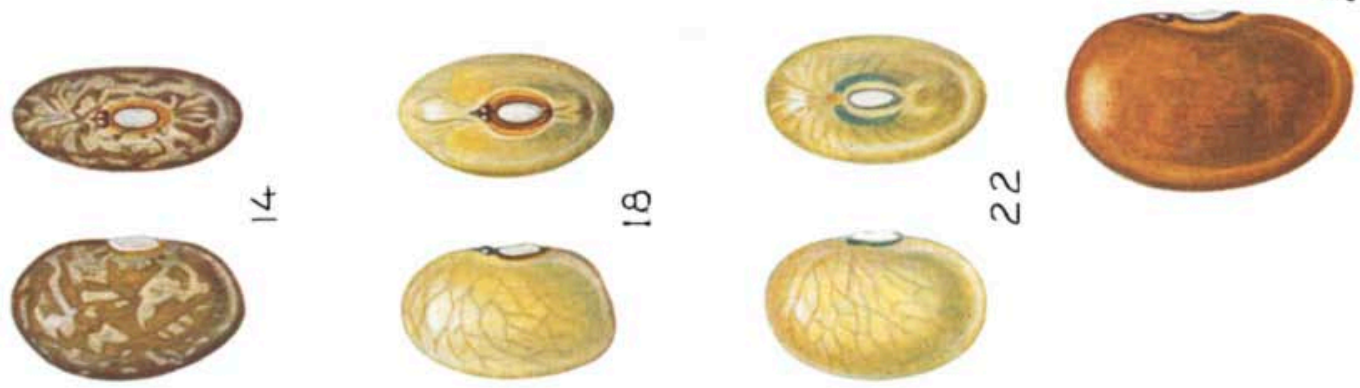

ก
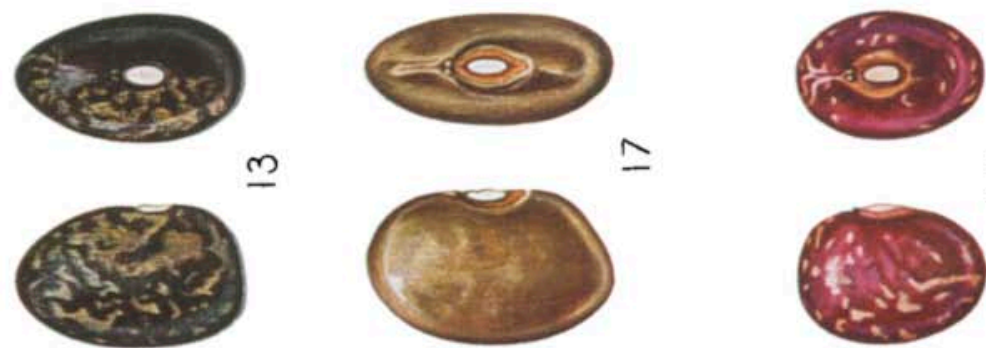

I

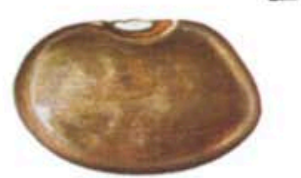

N

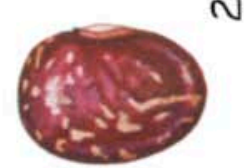




\section{LITERATURE CITED.}

Emerson R. A., 1902. Preliminary account of variation in bean hybrids

(15th. Ann. Rept. Nebr. Agr. Expt. Stat. S. 30-43).

Emerson R. A., 1904. Heredity in bean hybrids (17th. Ann. Rept. Nebr. Agr. Expt. Stat. p. 33-68).

Emerson R. A.. 1909a. Factors for mottling in beans (Ann. Rept. Am. Breeders Ass. V. p. 368-376).

Emerson R. A., 1909b. Inheritance of color in the seeds of the common bean (22 d. Ann. Rept. Nebr. Agr. Expt. Stat. p. 67-101).

Fruwirth C., 1919. Handbuch der landwirtschaftlichen Pflanzenzüchtung. Band III. Dritte Auflage (Berlin, P. Parey, 1919).

HaRLAND C. S., 1919. Inheritance of certain characters in the cowpea, Vigna sinensis (Journ. Genetics. VIII. p. 101-132).

Kajanus B., 1914. Zur Genetik der Samen von Phaseolus vulgaris (Zschr. f. Pflanzenzüchtung. II. P. 377-388).

Koolman H. N. 1920. Over de erfelijkheid van de kleur der zaadhuid van Phaseolus vulgaris (Diss. Uaiv. Utrecht. Bussum C. A. J. v. Dishoeck, 1920).

LUNDBERg J. F. och AAKERMAN A., 1917. Jakttagelser rörande fröfärgen hos avkommen av en spontan korsning mellan tvenne former av Phaseolus vulgaris (Sveriges Utsädesfören. Tidsskr. XXVII, p. 115-121).

MANN A., 1914. Coloration of the seedcoat of cowpeas (Journ. agr. Research II. p. 33-56).

Mendel G. J.. 1865. Versuche über Pflanzenhybriden (Verbandl. naturf, Ver. Brünn. IV. p. 3-47).

ReINKe J., 1915. Eine bemerkenswerte Knospenvariation der Feuerbohne nebst allgemeinen Bemerkungen über Allogonie (Ber. Deutsch. Botan. Gesellsch. XXXIII p. 324-348).

Shaw J. K. and J. B. Norton, 1918. The inheritance of seed coat colours in garden beans (Mass. Agr. Expt. Stat. Bull 185, p. 59-104).

Shull G. H., 1907. Some latent characters in a white bean (Science 1907, p. $828-832$ ).

ShUlL G H., 1908. A new mendelian ratio and several types of latency (Amer. Natural. XLII, p. 433-451').

Sirks M. J., 1920. De analyse van een spontane boonenhybride (Genetica II, p. $97-114)$.

SPIllman W. J., 1913. Colour correlations in cowpeas (Science XXXVIII, p. 302--304).

TJEbBes K. en H. N. Koolman, 1919. Erfelijkheidsonderzoekingen bij boonen I en II (Genetica I, p. 323-346).

Tuebbes K. en H. N. Koolman, 1921. Erfelijkheidsonderzoekingen bij boonen, 
138 SIRKS, THE COLOURFACTORS OF THE SEEDCOAT IN PHASEOLUS.

IV. Over den strepingsfacror. Een geval van volkomen afstooting tusschen twee factoren. V. Analyse eener spontane kruising van de stokkievitsboon (Genetica III, p. 28-49).

Tracy W. W. JR., 1907. American varieties of garden beans (U. S. Dept. Agr. Bur. Plantindustry. Bull. 109. 173 pp.).

Tschermak E., 1901. Weitere Beiträge zur Verschiedenwertigkeit der Merkmale bei Kreuzung von Erbsen und Bohnen (Zschr. f. d. Landw. Versuchswesen Oesterr. IV. p. 641-735).

Tschermak E., 1902. Ueber die gesetzmässige Gestaltungsweise der Mischlinge (Zschr. f.d. landw. Versuchswesen Oesterr. V. Sep. 80 pp.).

Tschermak E, 1904. Weitere Kreuzungsstudien an Erbsen, Levkojen und Bohnen (Zschr. f. d. landw. Versuchswesen Oesterr. VII. p. 533-638). Tschermak E., 1912. Bastardierungsversuche an Erbsen, Levkojen und Bohnen (Zschr. und Abstamm. v. Vererb. Lehre VII. p. 81-234).

Tschermak E., 1919. Bastardierungsversuche mit der grünsamigen ChevrierBohne (Zschr. f. Pflanzenzüchtung VII. p. 57-61). 

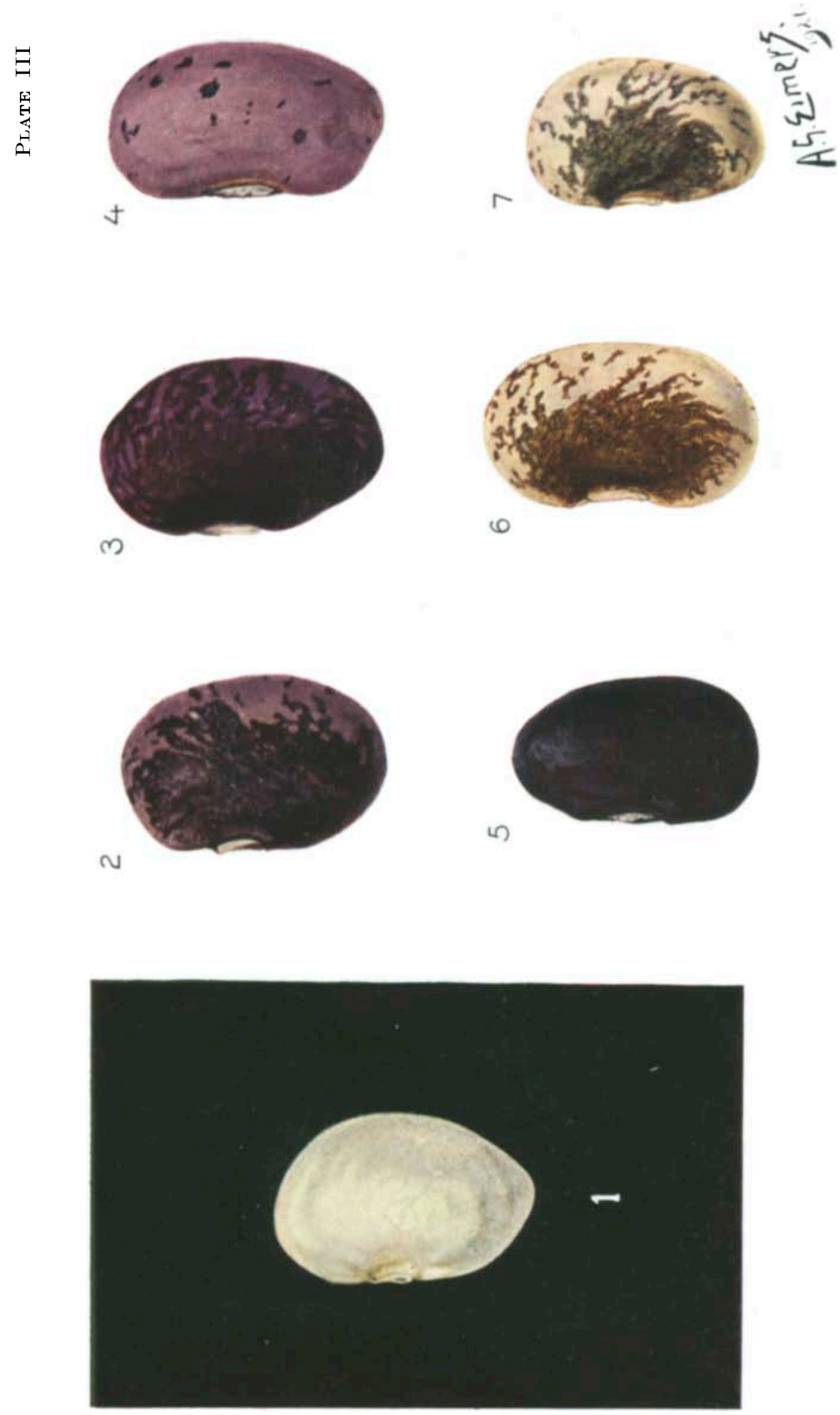